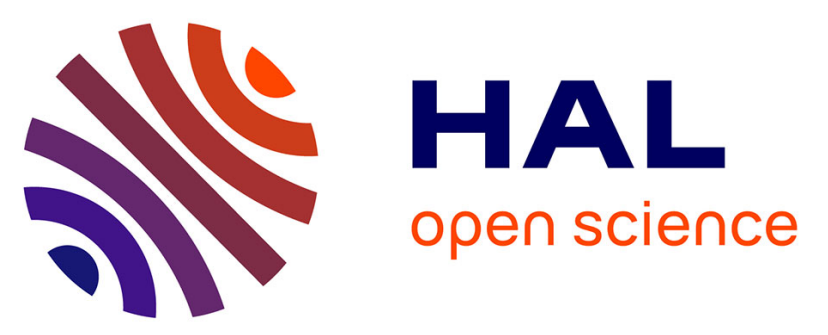

\title{
2-Mercaptobenzimidazole-functionalized chitosan for enhanced removal of methylene blue: batch and column studies
}

Khalid Elwakeel, Ahmed Elgarahy, Abdullah Al-Bogami, Mohammed Hamza, Eric Guibal

\section{To cite this version:}

Khalid Elwakeel, Ahmed Elgarahy, Abdullah Al-Bogami, Mohammed Hamza, Eric Guibal. 2Mercaptobenzimidazole-functionalized chitosan for enhanced removal of methylene blue: batch and column studies. Journal of Environmental Chemical Engineering, 2021, 9 (4), pp.105609. 10.1016/j.jece.2021.105609 . hal-03218182

\section{HAL Id: hal-03218182 \\ https://hal.mines-ales.fr/hal-03218182}

Submitted on 11 Nov 2021

HAL is a multi-disciplinary open access archive for the deposit and dissemination of scientific research documents, whether they are published or not. The documents may come from teaching and research institutions in France or abroad, or from public or private research centers.
L'archive ouverte pluridisciplinaire HAL, est destinée au dépôt et à la diffusion de documents scientifiques de niveau recherche, publiés ou non, émanant des établissements d'enseignement et de recherche français ou étrangers, des laboratoires publics ou privés.

\section{(ㄷ)(1) $\$$}

Distributed under a Creative Commons Attribution - NonCommerciall 4.0 International 


\title{
2-Mercaptobenzimidazole-functionalized chitosan for enhanced removal of methylene blue: Batch and column studies
}

\author{
Khalid Z. Elwakeel ${ }^{\mathrm{a}, \mathrm{b},{ }^{*} \mathrm{c}, 1}$, Ahmed M. Elgarahy ${ }^{\mathrm{b}, 2}$, \\ Abdullah S. Al-Bogami ${ }^{\mathrm{a}, 3}$, Mohammed F. Hamza ${ }^{\mathrm{c}, \mathrm{d}, 4}$, Eric Guibal ${ }^{\mathrm{e}, *, 5}$ \\ ${ }^{\text {a }}$ University of Jeddah, College of Science, Department of Chemistry, Jeddah, Saudi Arabia \\ ${ }^{\mathrm{b}}$ Environmental Science Department, Faculty of Science, Port-Said University, Port-Said, Egypt \\ ${ }^{c}$ Guangxi Key Laboratory of Processing for Non-Ferrous Metals and Featured Materials, School of Resources, Environment and Materials, Guangxi University, Nanning \\ 530004, PR China \\ ${ }^{\mathrm{d}}$ Nuclear Materials Authority, POB530, El-Maadi, Cairo, Egypt \\ ${ }^{\mathrm{e}}$ Polymers Composites and Hybrids (PCH), IMT Mines Ales, Alès, France
}

\begin{abstract}
Chitosan functionalized with 2-mercaptobenzimidazole (2-MBI) (i.e. 2-MBI@Chit) shows high sorption capacity (i.e., $1.28 \mathrm{mmol} \mathrm{MB} \mathrm{g}^{-1}$ ) for methylene blue (MB) (at pH close to 9.3). Sorption is weakly decreased (by less than $25 \%$ ) by high $\mathrm{NaCl}$ concentration (up to $45 \mathrm{~g} \mathrm{~L}^{-1}$ ). The sorption (slightly endothermic) is fitted by the Langmuir equation. The kinetic profile is fitted by the pseudo-first order rate equation (PFORE): equilibrium reached within $90 \mathrm{~min}$ of contact. The resistance to film diffusion is minimized when setting agitation speed at $200 \mathrm{rpm}$. Dye desorption is successfully achieved (up to $94.5 \%$ ) using $0.8 \mathrm{M} \mathrm{HCl}$; desorption kinetics is little slower than the sorption step. The loss in sorption capacity at the fifth sorption/desorption cycle does not exceed 5\%. Yoon-Nelson, Bohart-Adams, and bed-depth service time equations are used for analyzing the breakthrough in fixed-bed columns. At the exhaustion of the column, the sorption capacity approaches the maximum sorption capacity in batch: all the reactive groups remain accessible in dynamic sorption mode. The dye is efficiently recovered from spiked seawater and the sorption performance is depreciated by less than $16 \%$ while comparing tap water and seawater under selected experimental conditions.
\end{abstract}

\section{Introduction}

Industrial development is producing a tremendous increase in the discharge of toxic and hazardous compounds such as dyes, heavy metals, pesticides, insecticides, hydrocarbons, and pharmaceutical molecules in the environment [1]. Even at trace levels, these pollutants may have dramatic impacts on different biota due to their recalcitrant, mutagenic, and carcinogenic nature [2]. The dying industry is considered one of the major contributors to the contamination of natural water resources [3]. As colored aromatic compounds, their impact can be explained by different effects: direct toxicity (carcinogenicity, mutagenicity), persistence, bioaccumulation, but also eutrophication, turbidity (which may impact aquatic flora) [4].

Industrial dyes are usually classified into three main groups considering their dissolution behavior in aqueous solutions: (a) anionic (acidic) dyes with completely negative charge due to $\mathrm{SO}_{3}^{-2}$ group (i.e. direct and reactive dyes), (b) cationic (basic) dyes with completely positive charge due to protonated $\mathrm{NH}_{2}$ group, and (c) non-ionic form (i. e. disperse dyes) [5]. Dyes are abundantly used in various industries such as cosmetics, medicine, plastic, paper, printing, pharmaceutical

\footnotetext{
* Corresponding author at: University of Jeddah, College of Science, Department of Chemistry, Jeddah, Saudi Arabia.

** Corresponding author.

E-mail addresses: kelwkeel@uj.edu.sa (K.Z. Elwakeel), ahmed.gamal@sci.psu.edu.eg (A.M. Elgarahy), aalbogami@uj.edu.sa (A.S. Al-Bogami), m_fouda21@ hotmail.com (M.F. Hamza), eric.guibal@mines-ales.fr (E. Guibal).

1 https://orcid.org/0000-0002-8853-284X.

${ }^{2}$ https://orcid.org/0000-0003-4959-2652.

3 https://orcid.org/0000-0002-8670-2729.

${ }^{4}$ https://orcid.org/0000-0002-8935-6884.

5 https://orcid.org/0000-0002-2767-6305.
} 
industries, perfumery, leather, varnishes, textile, and so on. The global consumption rate was estimated close to $10^{7} \mathrm{~kg}$ /year [6]. More than 400,000 tons of reactive dyes are mainly used to dye cellulosic fiber especially cotton; dyeing $1 \mathrm{~kg}$ of cotton produces $200 \mathrm{~kg}$ of wastewater containing up to $50 \%$ of dye's initial feed [7].

Persistence of these released dyed effluents and/or their decomposition products in the water bodies seriously endangers the health of different living creatures [8]. They deteriorate water quality (specification) by changing the chemical oxygen demand (COD), biological oxygen demand (BOD), total dissolved solids (TDS), total suspended solids (TSS) and ultimately result in the diminishment of photosynthesis efficiency due to an increase in the water turbidity. Additionally, dyes mostly display mutagenic and carcinogenic features [9]. Methylene blue (MB) is an emblematic example of toxic cationic dye, chemically named tetramethylthionine chloride with the chemical formula of $\mathrm{C}_{16} \mathrm{H}_{18} \mathrm{~N}_{3} \mathrm{SCl}$. It is extensively used in a variety of industrial processes such as cosmetics, hygienic, textiles, paper coatings, and pesticide industries [10]. A large intake of toxic $\mathrm{MB}(>7.0 \mathrm{mg} / \mathrm{kg})$ may result in severe threats including headache, abdominal pain, high blood pressure (hypertension), gastritis, jaundice, respiratory distress, painful micturition, mental disorder, nausea, vomiting, and methemoglobinemia-like syndromes [11].

Many techniques have been developed for the treatment of dyebearing effluents including ion exchange [12], chemical precipitation [13], coagulation/ flocculation [14,15], ozonation [16], membrane filtration [17], solvent extraction [18], and photocatalytic degradation [19]. The implementation of these sophisticated strategies frequently faces important drawbacks and constraints such as high operational cost, inefficiency for low pollutant concentrations, toxic intermediates products, reagents consumption, or sewage sludge formation. Biosorption constitutes a promising alternative technique for wastewater treatment because of its environmental friendliness and versatility [20, 21]. Indeed, this bioprocess is characterized by remarkable merits, including availability, biodegradability, cost-effectiveness, efficiency, flexibility, simplicity, and reusability. In the case of $\mathrm{MB}$, recent literature highlighted the many possibilities offered by biosorbent-based sorbents or inorganic nanomaterial systems such as alginate/clinoptilolite composite [22], bentonite-ZnO-CuO nanocomposite [23], ball-milled biochar [24], fungal biomass [25], iron nanoparticles [26], pectin-based hydrogels [27].

Chitosan (CS) (constituted of 2-acetamido-2-deoxy- $\beta-D$ -glucopyranose and 2-amino-2-deoxy- $\beta-\mathrm{D}$-glucopyranose residues) is produced by the deacetylation of chitin, naturally occurring in the exoskeletons of crustaceous (i.e. crayfish, crab, cuttlefish, shrimp shells, squids and oyster), fungal cell wall, and insect cuticles [28]. Chitosan-based sorbents are regarded as a cornerstone in various wastewater treatments because of their well-known strong affinity towards different water pollutants (i.e. organic dyes, heavy metals, and pharmaceuticals) thanks to the remarkable abundance of amine $\left(-\mathrm{NH}_{2}\right)$ and hydroxyl $(-\mathrm{OH})$ groups on its structural backbone $[29,30]$. However, major drawbacks are still associated with the usage of CS-based materials, including low surface area, chemical instability (dissociation) in an acidic environment, colloids formation in water, poor mechanical property, and possible degradation by chemical and/or microbial actions. Interestingly, structural improvement of CS (by crosslinking and/or intercalation with other materials to fabricate bio-composites whether by grafting, blending, and incorporation of CS with other materials) can economically offer the opportunity to overcome these operational limitations [31]. Numerous cross-linkers agents may be used for reinforcing the stability of chitosan, such as epichlorohydrin, glutaraldehyde, ethylene glycol diglycidyl ether, sulfuric acid, and sodium tripolyphosphate. The decline in the reactivity of cross-liked $\mathrm{CS}$, resulting from consumption of available binding $\left(-\mathrm{NH}_{2}\right)$ groups during the cross-linking process can be compensated by the introduction of new binding sites [32,33].

2-Mercaptobenzimidazole (2-MBI), with the chemical formula of
$\mathrm{C}_{7} \mathrm{H}_{6} \mathrm{~N}_{2} \mathrm{~S}$ (Molecular weight of $150.2 \mathrm{~g} / \mathrm{mol}$ ), is a heterocyclic organic compound containing two electron donor atoms: nitrogen $(\mathrm{N})$ and sulfur (S). This compound has been extensively utilized in a diversity of biological and pharmaceutical activities such as anti-bacterial, anti-cancer, enzyme inhibition, anti-inflammatory, anti-microbial and anti-ulcer activities [34]. Furthermore, it is widely used in non-biological approaches such as anti-oxidant for rubber and plastics, corrosion inhibitors, chelating collectors of some low-grade sulfide minerals [35], and analytical reagents for the determination of various transition metal ions such as $\mathrm{Hg}(\mathrm{II}), \mathrm{Fe}(\mathrm{II})$ and $\mathrm{Cd}(\mathrm{II})$. Although, 2-MBI was mainly used for developing corrosion inhibitors, this functionalizing agent (or its analog, 2-MTI, 2-mercaptobenzothiazole) was also used for enhancing the sorption properties of synthetic and bio-based supports [36]. For example, 2-MTI was immobilized on cellulose [37] and synthetic resin for palladium uptake [38]. For rubidium recovery, Guerra et al. [39] used organoclays for the immobilization of MBI. Recently, Mesa et al. [40] reported the immobilization of 2-MBI onto ion-imprinted acrylic acid-based polymer and the removal of methylmercury.

Different techniques were used for immobilizing 2-mercaptobenzimidazole on chitosan-based sorbents, including impregnation mediated by acetone [41], or chemical grafting [42].

The current work investigates the sorption properties of chitosan functionalized with 2-MBI for MB. This is a companion work to another study that focused on the sorption of silver using magnetic (or nonmagnetic) chitosan functionalized with 2-MBI [42]. Complementary characterization techniques are used, including for the interpretation of MB binding mechanisms. The second part of the work focuses on the extensive study of sorption properties; including the study of $\mathrm{pH}$ effect, sorbent dosage, agitation speed, presence of high salt concentrations; uptake kinetics. The thermodynamics of MB sorption is investigated through sorption isotherms at different temperatures. Dye desorption and sorbent recycling are investigated. In the last part of the work, the impact of solution complexity is evaluated by comparison of sorption properties with spiked solutions of increasing complexity (tap water and seawater).

\section{Materials and methods}

\subsection{Materials}

Chitosan, 2-mercaptobenzimidazole (2-MBI), epichlorohydrin (99\%, w/w) were purchased from Sigma-Aldrich (Merck, Darmstadt, Germany). Methylene Blue (MB, 97\%) was analytical reagent (AR) grade and supplied by Merck India (Mumbai, India).

\subsection{Synthesis of sorbent (2-MBI@Chit)}

The synthesis of 2-MBI@Chit has been already reported [42] (Scheme S1, see Supplementary information). Briefly, chitosan (5.6 g) and 2-MBI $(6.1 \mathrm{~g})$ were dispersed in $250 \mathrm{~mL}$ of Milli-Q water under strong agitation (1000 rpm for $30 \mathrm{~min}$ in a $500 \mathrm{~mL}$ two-necked round-bottomed flask). Epichlorohydrin $(4.75 \mathrm{~mL})$ was then added under strong stirring and heating at $70^{\circ} \mathrm{C}$ for three hours. After filtration and abundant water rinsing, the solid was dried under vacuum for $6 \mathrm{~h}$ at $50{ }^{\circ} \mathrm{C}$. It is noteworthy that the reaction is almost quantitative $(17.1 \mathrm{~g}$ 2-MBI@Chit for $17.3 \mathrm{~g}$ of precursors).

\subsection{Characterization of materials}

The characteristics (and the methods whereof) of 2-MBI@Chit have already been documented [42]. Additional characterization was performed for the interpretation of the interactions of 2-MBI@Chit with MB. The FTIR spectra were collected on a Nicolet IS10 FTIR (Thermo Fischer Scientific, Waltham, MA, USA), equipped with an attenuated total reflectance tool. SEM microphotographs were acquired on a scanning electron microscope (Jeol Ltd.; JSM-6510LV, Tokyo, Japan). 


\subsection{Sorption tests}

\subsubsection{Batch tests}

The study of MB sorption was performed in a batch system. For all sorption studies, the process was comprehensively run by varying one of the affecting operational parameters, while keeping the other environmental conditions fixed. The standard conditions corresponded to initial dye concentration of $100 \mathrm{mg} \mathrm{MB} \mathrm{L}^{-1}$ (i.e., $\mathrm{C}_{0}: 0.313 \mathrm{mmol} \mathrm{MB} \mathrm{L}{ }^{-1}$ ), $\mathrm{pH}$ of 9.3 , sorbent dosage (SD) of $1.5 \mathrm{~g} \mathrm{~L}^{-1}$, contact time (time) of $90 \mathrm{~min}$, agitation speed (v) of $200 \mathrm{rpm}$ (Rota bit, J.P. Selecta, Abrera, Spain), and room temperature (i.e., $25 \pm 1^{\circ} \mathrm{C}$ ). Specific experimental conditions are systematically reported in the caption of the figures (see below). After withdrawing and centrifuging the samples, they were analyzed by spectrophotometry at $\lambda_{\text {max }}: 664 \mathrm{~nm}$ [43], using a Palintest $7100 \mathrm{spec}-$ trophotometer (Palintest, Ltd., Gateshead, UK). The sorption capacity $\left(\mathrm{q}, \mathrm{mmol} \mathrm{g}^{-1}\right.$ ) was deduced from the mass balance equation:

$q=\frac{\left(C_{0}-C_{e q}\right)}{S D}$

where $\mathrm{C}_{\mathrm{eq}}$ is the residual dye concentration $\left(\mathrm{mmol} \mathrm{L}^{-1}\right)$.

For the study of the $\mathrm{pH}$ effect, the initial $\mathrm{pH}$ values $\left(\mathrm{pH}_{0}\right)$ were varied between 1.9 and 10.5. The $\mathrm{pH}$ was not controlled during the sorption, but the equilibrium $\mathrm{pH}$ values were recorded $\left(\mathrm{pH}_{\mathrm{eq}}\right)$, using an Aqualytic AL15 pH-meter (Aqualytic GmbH \& Co, Dortmund, Germany). For investigating the impact of sorbent dosage, the SD was varied between 0.5 and $5 \mathrm{~g} \mathrm{~L}^{-1}$. The analysis of agitation speed was carried out varying the agitation from 50 to $300 \mathrm{rpm}$. For the sorption isotherms, the initial dye concentration was varied between 0.0313 and $3.13 \mathrm{mmol} \mathrm{MB} \mathrm{L}^{-1}$. Sorption isotherms were performed at temperatures ranging between $25^{\circ} \mathrm{C}$ and $55^{\circ} \mathrm{C}$ (samples being agitated in a shaking incubator LSI3016R, LabTech S.r.l., Sorisole (BG), Italy). For the evaluation of interfering ions (herein $\mathrm{NaCl}$ ), the same experimental procedure was used, complementing the solution with increasing amounts of salt (corresponding to concentrations in the range: $0.085 \mathrm{~mol} \mathrm{~L}^{-1}$ to $0.77 \mathrm{~mol} \mathrm{~L}^{-1}$ ).

For uptake kinetics, $1 \mathrm{~L}$ of dye solution was mixed with $1.5 \mathrm{~g}$ of 2 MBI@Chit for $180 \mathrm{~min}$, samples were collected affixed contact times, filtrated and analyzed for residual concentrations, and the concentration of the dye in the sorbent was calculated by the decrement method:

$q(t)=\sum_{i=1}^{n} \frac{\left(C(t)_{(i-1)}-C(t)_{(i)}\right) \times V(t)_{(i-1)}}{m}$

where $C(t)_{(\mathrm{i})}\left(\mathrm{mmol} \mathrm{MB} \mathrm{L}^{-1}\right)$ is the MB concentration of the withdrawn sample number $i$ at time $t$ and $C(t)_{(0)}=C_{0}, V(t)(i)(\mathrm{mL})$ is the volume of the solution in the flask at sample number $i$ and time $t$, and $m$ is the mass of the sorbent in the flask. Here, $V(t)_{(i)}-V(t)_{(i-1)}$ equals $5 \mathrm{~mL}$ (the sample volume).

The same batch process was used for the investigation of dye desorption and sorbent recycling. The MB-loaded 2MBI@Chit sorbents (recovered from sorption tests) were first washed for removing absorbed dye. In a second step, the sorbent was mixed with $0.5 \mathrm{M} \mathrm{HCl}$ solution (SD: $3 \mathrm{~g} \mathrm{~L}^{-1}$ ) for $140 \mathrm{~min}$. The suspension was centrifuged; the supernatant was analyzed for residual MB concentration. The collected sorbent was repeatedly rinsed with distilled water until the $\mathrm{pH}$ of rinsing water reached 7. The regenerated sorbent was dried for $2 \mathrm{~h}$ at $40{ }^{\circ} \mathrm{C}$ in an oven (Gallenkamp BS Model OV-160, Loughborough (LE), UK) and subjected for 5 consecutive sorption-desorption cycles. The desorption efficiency (DE, \%) was determined by:

$\begin{aligned} D E \quad(\%)= & \frac{\text { Amount of desorbed } M B \quad(\mathrm{mmol}) \quad \text { into the eluate solution }}{\text { Amount of sorbed } M B \quad(\mathrm{mmol})} \\ & \times 100\end{aligned}$

Final tests were performed on MB-spiked real effluents (concentration of $\mathrm{MB}$ was varied between 0.03 and $0.12 \mathrm{mmol} \mathrm{MB} \mathrm{L}^{-1}$ ), using either tap water (collected from Water Supply facilities at PortSaid, Egypt) or seawater collected in the Red Sea coast (Jeddah, Saudi Arabia) to evaluate the impact of the complexity of the solution (background ions) on MB sorption.

All sorption tests were performed in triplicate, and the averages were recorded. The limit of experimental errors on triplicates was systematically below $5 \%$.

The modeling of uptake kinetics and sorption isotherms are performed using a series of conventional models summarized in Tables 1 and 2 . The parameters were determined by non-linear regression analysis using the facilities offered by Mathematica ${ }^{\circledR}$ (Wolfram Research, Champaign (IL), USA). The comparison of models was based on the determination coefficients (i.e., $\mathrm{R}^{2}$ ) and the Akaike Information Criterion (AIC, see Table 1).

\subsubsection{Fixed-bed column tests}

The dynamic sorption tests were performed in fixed-bed systems using plastic columns (diameter: $1 \mathrm{~cm}$; height: $10 \mathrm{~cm}$ ). A small piece of glass wool was placed at the bottom of the column and a known quantity of the sorbent was placed in the column to yield the desired bed height (m: $1 \mathrm{~g}, \mathrm{BV}: 1.92 \mathrm{~cm}^{3}$, H: $2.45 \mathrm{~cm}$; m: $2 \mathrm{~g}$; BV: $3.84 \mathrm{~cm}^{3}$, H: $4.89 \mathrm{~cm}$; m: $3 \mathrm{~g}$; BV: $5.76 \mathrm{~cm}^{3}$, H: $\left.7.34 \mathrm{~cm}\right)$. The MB solution $(0.625 \mathrm{mM})$ was pumped downward through the column at the desired flow rate $(2,4$, or $6 \mathrm{~mL} \mathrm{~min}^{-1}$ ). Samples were collected from the outlet of the column at different time intervals and analyzed for residual dye concentration. The operation of the column was stopped when the outlet metal ion

Table 1

Uptake kinetics - model parameters.

\begin{tabular}{|c|c|c|}
\hline Model & Parameter & Value \\
\hline $\begin{array}{l}\text { Experimental } \\
\text { value }\end{array}$ & $\mathrm{q}_{\text {eq,exp. }}\left(\mathrm{mmol} \mathrm{g}{ }^{-1}\right)$ & 0.1933 \\
\hline \multirow[t]{2}{*}{ PFORE } & Equation [86] & $q(t)=q_{e q, 1}\left(1-e^{-k_{1} t}\right)$ \\
\hline & $\begin{array}{l}\mathrm{q}_{\mathrm{eq}, 1}\left(\mathrm{mmol} \mathrm{g}^{-1}\right) \\
\mathrm{k}_{1} \times 10^{2}\left(\mathrm{~min}^{-1}\right) \\
\mathrm{R}^{2} \\
\text { AIC }\end{array}$ & $\begin{array}{l}0.1936 \\
4.14 \\
0.996 \\
-165\end{array}$ \\
\hline \multirow[t]{4}{*}{ PSORE } & Equation [86] & $q(t)=\frac{q_{e q, 2}^{2} k_{2} t}{1+k_{2} g_{e q 2} t}$ \\
\hline & $\begin{array}{l}\mathrm{q}_{\mathrm{eq}, 2}\left(\mathrm{mmol} \mathrm{g}^{-1}\right) \\
\mathrm{k}_{2} \times 10\left(\mathrm{~g} \mathrm{mmol}^{-1}\right. \\
\left.\min ^{-1}\right)\end{array}$ & $\begin{array}{l}0.2225 \\
2.38\end{array}$ \\
\hline & $\mathrm{R}^{2}$ & 0.991 \\
\hline & AIC & -148 \\
\hline \multirow[t]{7}{*}{ RIDE } & Equation [59] & \\
\hline & & $\frac{q(t)}{q_{e q}}=1-$ \\
\hline & & $6 \alpha(\alpha+1) \exp f_{0}\left(\frac{-D_{e} q_{n}^{2}}{r^{2}} t\right)$ \\
\hline & & $\begin{array}{l}\sum_{n=1} \frac{9+9 \alpha+q_{n}^{2} \alpha^{2}}{\text { With } q_{n} \text { being the non-zero roots of }}\end{array}$ \\
\hline & $\begin{array}{l}\mathrm{D}_{\mathrm{e}} \times 10^{11}\left(\mathrm{~m}^{2}\right. \\
\left.\mathrm{min}^{-1}\right)\end{array}$ & $\begin{array}{l}\tan q_{n}=\frac{3 q_{n}}{3+\alpha q_{n}^{2}} \text { and } \frac{m q}{V C_{0}}=\frac{1}{1+\alpha} \\
7.62\end{array}$ \\
\hline & $\mathrm{R}^{2}$ & 0.983 \\
\hline & AIC & -123 \\
\hline
\end{tabular}

$\mathrm{q}_{\mathrm{t}}\left(\mathrm{mmol} \mathrm{g}^{-1}\right)$ : amount of dye sorbed at time $(\mathrm{t}) ; \mathrm{q}_{\mathrm{eq}}\left(\mathrm{mmol} \mathrm{g}^{-1}\right)$ : sorption capacity at equilibrium; $\mathrm{k}_{1}\left(\mathrm{~min}^{-1}\right)$ : apparent PFORE rate constant; $\mathrm{k}_{2}\left(\mathrm{~g} \mathrm{mmol}^{-1}\right.$ $\left.\mathrm{min}^{-1}\right)$ : apparent PSORE rate constant; $\mathrm{D}_{\mathrm{e}}\left(\mathrm{m}^{2} \mathrm{~min}^{-1}\right)$ : Effective diffusivity coefficient; $r(m)$ : Radius of sorbent particle. The comparison of models was performed using the Akaike Information Criterion, AIC [87]:

$A I C=N \ln \left(\frac{\sum_{i=0}^{N}\left(y_{i, \text { exp. }}-y_{i, \text { model }}\right)^{2}}{N}\right)+2 N_{p}+\frac{2 N_{p}\left(N_{p}+1\right)}{N-N_{p}-1}$

where $\mathrm{N}$ is the number of experimental points, $\mathrm{N}_{\mathrm{p}}$ the number of model parameters, $\mathrm{y}_{\mathrm{i} \text {,exp. }}$ and $\mathrm{y}_{\mathrm{i} \text {,model }}$ the experimental and calculated values of the tested variable. 
Table 2

Sorption isotherms - model parameters [88].

\begin{tabular}{|c|c|c|c|c|c|}
\hline Model & Parameter & $\begin{array}{l}\mathrm{T}: \\
25{ }^{\circ} \mathrm{C}\end{array}$ & $\begin{array}{l}\mathrm{T}: \\
35^{\circ} \mathrm{C}\end{array}$ & $\begin{array}{l}\mathrm{T}: \\
45^{\circ} \mathrm{C}\end{array}$ & $\begin{array}{l}\mathrm{T}: \\
55{ }^{\circ} \mathrm{C}\end{array}$ \\
\hline $\begin{array}{l}\text { Experimental } \\
\text { value }\end{array}$ & $\begin{array}{l}\mathrm{q}_{\mathrm{m}, \text { exp. }} \\
\left(\mathrm{mmol} \mathrm{g}^{-1}\right)\end{array}$ & 1.281 & 1.294 & 1.307 & 1.322 \\
\hline \multirow[t]{5}{*}{ Langmuir } & Equation [89] & \multicolumn{4}{|c|}{$q_{e q}=\frac{q_{m, L} C_{e q}}{2}$} \\
\hline & $\mathrm{q}_{\mathrm{m}, \mathrm{L}}\left(\mathrm{mmol} \mathrm{g}^{-1}\right)$ & 1.502 & 1.496 & 1.484 & 1.485 \\
\hline & $\mathrm{b}_{\mathrm{L}}\left(\mathrm{L} \mathrm{mmol}^{-1}\right)$ & 6.80 & 7.72 & 8.93 & 10.5 \\
\hline & $\mathrm{R}^{2}$ & 0.997 & 0.997 & 0.996 & 0.995 \\
\hline & AIC & -138 & -142 & -140 & -132 \\
\hline \multirow[t]{5}{*}{ Freundlich } & Equation [90] & \multicolumn{4}{|c|}{$q_{e q}=k_{F} C_{e q}^{1 / n_{F}}$} \\
\hline & $\mathrm{k}_{\mathrm{F}}$ & 1.408 & 1.438 & 1.464 & 1.504 \\
\hline & $\mathrm{n}_{\mathrm{F}}$ & 2.31 & 2.37 & 2.43 & 2.53 \\
\hline & $\mathrm{R}^{2}$ & 0.934 & 0.931 & 0.929 & 0.922 \\
\hline & AIC & -83 & -82 & -82 & -80 \\
\hline \multirow[t]{7}{*}{ Sips } & Equation [88] & \multicolumn{4}{|c|}{$q_{m, S} b_{S} C_{e q}^{1 / n_{S}}$} \\
\hline & & \multicolumn{4}{|c|}{$\overline{1+b_{S} C_{e q}^{1 / n_{s}}}$} \\
\hline & $\mathrm{q}_{\mathrm{m}, \mathrm{L}}\left(\mathrm{mmol} \mathrm{g}^{-1}\right)$ & 1.399 & 1.395 & 1.395 & 1.406 \\
\hline & $\mathrm{b}_{\mathrm{L}}\left(\mathrm{L} \mathrm{mmol}^{-1}\right)$ & 11.74 & 13.78 & 15.38 & 17.65 \\
\hline & $\mathrm{n}_{\mathrm{F}}$ & 0.854 & 0.852 & 0.998 & 0.876 \\
\hline & $\mathrm{R}^{2}$ & 0.998 & 0.999 & 0.866 & 0.996 \\
\hline & AIC & -155 & -162 & -146 & -134 \\
\hline
\end{tabular}

$\mathrm{C}_{\mathrm{e}}\left(\mathrm{mmol} \mathrm{L}^{-1}\right)$ : equilibrium concentration of dye in solution; $\mathrm{q}_{\mathrm{eq}}\left(\mathrm{mmol} \mathrm{g}^{-1}\right)$ : dyes sorption capacity at equilibrium; $\mathrm{q}_{\mathrm{m}, \mathrm{L}}\left(\mathrm{mmol} \mathrm{g}^{-1}\right)$ : maximum sorption capacity at saturation of the monolayer (Langmuir); $b_{\mathrm{L}}\left(\mathrm{L} \mathrm{mmol}^{-1}\right)$ : Langmuir constant related to dye affinity for reactive groups; $\mathrm{k}_{\mathrm{f}}\left(\mathrm{mmol} \mathrm{g}^{-1}\right)\left(\mathrm{L} \mathrm{mmol}^{-1}\right)^{1 / \mathrm{n}}$ : Freundlich constant relative sorption capacity; $\mathrm{n}_{\mathrm{F}}$ : Freundlich constant related to the sorption capacity and intensity; $\mathrm{q}_{\mathrm{m}, \mathrm{s}}\left(\mathrm{mmol} \mathrm{g}^{-1}\right)$ : maximum sorption capacity at saturation of the sorbent (Sips); $b_{S}\left(\mathrm{~L} \mathrm{mmol}^{-1}\right)$ : Sips constant related to dye affinity for reactive groups; $\mathrm{n}_{\mathrm{S}}$ : Sips exponent related to the sorption capacity and intensity.

concentration reached its initial concentration.

The Yoon and Nelson model was used for simulating the breakthrough curves $\left(\mathrm{C}(\mathrm{t}) / \mathrm{C}_{0}\right)$ vs. time or BV (bed volume: Volume passed through the column/volume of fixed bed) [44]:

$\ln \left(\frac{C(t)}{C_{0}-C(t)}\right)=k_{Y N}(t-\tau)$,

where $\mathrm{k}_{\mathrm{YN}}$ is the Yoon \& Nelson rate coefficient $\left(\mathrm{min}^{-1}\right)$, $\mathrm{t}$ is the service time ( $\mathrm{min}$ ) and $\tau(\mathrm{min})$ corresponds to the required time for reaching the $50 \%$ sorbate breakthrough.

The breakthrough curves were also analyzed using the bed-depth service time model (BDST, [45]) derived from the Adams-Bohart model [46]:

$\ln \left(\frac{C_{0}}{C_{s}}-1\right)=\ln \left[e^{k_{B D S T} N_{0} H / u}-1\right]-k_{B D S T} C_{0} t_{s}$,

where $u$ is the linear volumetric flow rate $\left(\mathrm{m} \mathrm{h}^{-1}\right)$; $\mathrm{t}$ is the service time at breakthrough (herein defined as $\mathrm{C}_{\mathrm{b}}=0.01 \mathrm{C}_{0}, \mathrm{~h}$ ); $\mathrm{H}$ the height of the column (m); $\mathrm{C}_{\mathrm{s}}$ is the exhaustion concentration (concentration at the outlet of the column corresponding to $0.95 \mathrm{C}_{0}, \mathrm{mmol} \mathrm{L}^{-1}$ ); $\mathrm{k}_{\mathrm{BDST}}$ is the BDST rate $\left(\mathrm{m}^{3} \mathrm{~mol}^{-1} \mathrm{~h}^{-1}\right)$, and $\mathrm{N}_{0}$ is the bed capacity $\left(\mathrm{mmol} \mathrm{L}^{-1}\right)$. Since the exponential term is usually much larger than unit, the Eq. (5a) can be reduced to:

$t_{s}=\frac{N_{0}}{C_{0} u} H-\frac{1}{k_{B D S T} C_{0}} \ln \left(\frac{C_{0}}{C_{S}}-1\right)$

The critical bed height $\left(\mathrm{H}_{0}, \mathrm{~m}\right)$ is deduced from Eq. (5b) setting the $\mathrm{t}_{\mathrm{s}}$ value to 0 :

$H_{0}=\frac{u}{k_{B D S T} N_{0} C_{0}} \ln \left(\frac{C_{0}}{C_{S}}-1\right)$

\section{Results and discussion}

\subsection{Characterization of sorbent}

\subsubsection{Reminder on the main characteristics of 2-MBI@Chit}

Previous studies have reported the textural properties of 2-MBI-Chit [42]. The specific surface area of the sorbent was $8.1 \mathrm{~m}^{2} \mathrm{~g}^{-1}$ (deduced from $\mathrm{N}_{2}$ sorption and desorption isotherm using BET measurements), while the pore size and volume were $24.5 \mathrm{~nm}$ and $0.033 \mathrm{~cm}^{3} \mathrm{~g}^{-1}$, respectively. The average particle size was determined by DLS measurements close to $486 \mu \mathrm{m}$. The zetametric measurements showed that the $\mathrm{pH}_{\mathrm{PZC}}$ is close to 8.3: the sorbent is protonated in acid media. The CHNS analysis (elemental analysis) revealed that sulfur content reaches $2.95 \mathrm{mmol} \mathrm{S} \mathrm{g}{ }^{-1}$ while the nitrogen content was $7.36 \mathrm{mmol} \mathrm{N} \mathrm{g}^{-1}$. Elwakeel et al. [42] commented that the theoretical N/S molar ratio (i. e., 2.49) is lower than expected (i.e., 3:1), based on the structure of 2 -MBI ( $2 \mathrm{~N}$ per $\mathrm{S}$ ) and the immobilization of a molecule of 2 -MBI per amine group on chitosan (for full substitution). This means that all the amine groups are not grafted by 2-MBI, probably because the proposed structure (which suggests interlinkage between 2 molecules of 2-MBI through epichlorohydrin) is not fully operative on each amine groups of chitosan (grafting only one MBI instead of two MBI groups).

Thermogravimetric analysis showed four phases in the thermal degradation of the sorbent: (a) water release $(\sim 6.7 \%$ up to $\left.130-140^{\circ} \mathrm{C}\right)$, (b) steep and important weight loss $(\sim 30 \%$, up to $280-290^{\circ} \mathrm{C}$ ), associated with the degradation of substituents on chitosan backbone, (c) progressive weight loss till $440{ }^{\circ} \mathrm{C}$ (degradation of chitosan backbone and char formation), and (d) decomposition of the char.

\subsubsection{SEM observations}

Fig. S1 compares the surface morphology of sorbent particles before and after MB sorption. Apparently, the surface appears to be smoothed after dye sorption. The sorbent (2-MBI@Chit) initially shows some irregular structures that bring porosity and greater surface area for exchange (right side of relevant micrograph). These irregularities are substantially decreased after dye uptake, with brighter micro-objects at the surface.

\subsubsection{FTIR characterization of the interactions between 2-MBI@Chit and $M B$}

Fig. S2 shows the FTIR spectra of 2-MBI@Chit before and after dye sorption. The global shape of the spectra does not change after dye uptake. Table S1 reports the main peaks and their assignments. The broad and intense band centered around $3440 \mathrm{~cm}^{-1}$ is assigned to the combined contributions of $-\mathrm{OH}$ and $-\mathrm{NH}$ groups. In the region $1200-900 \mathrm{~cm}^{-1}$, the broad band with several peaks represents the fingerprint of the carbohydrate ring of chitosan [47]. The absence of relevant peaks at $962 \mathrm{~cm}^{-1}$ and $925 \mathrm{~cm}^{-1}$, which are representative of the $\mathrm{C}-\mathrm{C}$ bonds of epoxide functions from epichlorohydrin [47], means that the epoxide ring was completely opened for grafting 2-MBI. This is consistent with the relatively high yield of the synthesis ( $>98 \%$ ). The FTIR spectrum of MB show abundant sharp peaks in the range $1700-800 \mathrm{~cm}^{-1}$ [48], which are superposed to the "peak forest" associated to 2-MBI/epichlorohydrin/chitosan system. It is thus difficult identifying precise changes; the most significant changes are associated with the decrease in the relative intensity of some peaks (Fig. 1 -spectra focused on $2000-400 \mathrm{~cm}^{-1}$ ). For example, the broad band centered at $1682 \mathrm{~cm}^{-1}$ is widened (with the intensification of the shoulder around $1645 \mathrm{~cm}^{-1}$ ). The relative intensity of the peak at $\sim 1565 \mathrm{~cm}^{-1}$ is reduced: $\mathrm{N}-\mathrm{H}$ functional groups are probably involved in dye binding. The relative intensities of the peaks at $1439 \mathrm{~cm}^{-1}$ (shoulder converted into a more marked peak), $1416 \mathrm{~cm}^{-1}$ (shifted to $1411 \mathrm{~cm}^{-1}$ ), and $1375 \mathrm{~cm}^{-1}$ (shifted to $1379 \mathrm{~cm}^{-1}$ ) are also decreased (in addition to shifts). These changes demonstrate that the environment of $\mathrm{N}-\mathrm{C}^{=} \mathrm{S}$ and $\mathrm{C}-\mathrm{O}$ reactive groups are affected by the sorption of the dye and that their 


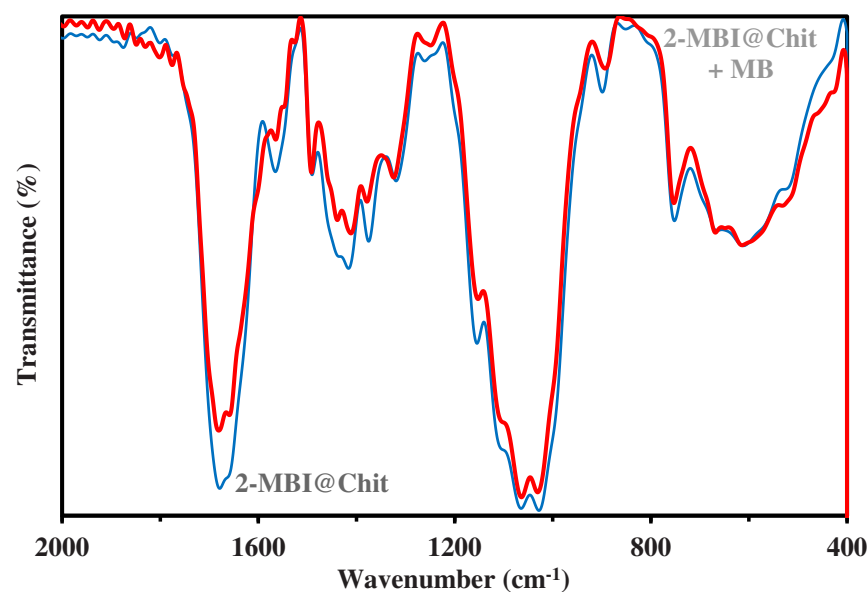

Fig. 1. FTIR spectra of 2-MBI@Chit before and after MB sorption (focus on the wavenumber range: $2000-400 \mathrm{~cm}^{-1}$ ).

respective reactive groups are involved in dye uptake. The interpretation of the sorption mechanism is made complex by the diversity of reactive groups but also the specific properties of the dye. Indeed, MB can readily appear under different resonance forms depending on the $\mathrm{pH}$, the temperature, and the redox conditions: the cationic charge may be localized on either the heterocyclic sulfur site or the exocyclic nitrogen atom [49]. In the case of $\mathrm{MB}$ sorption onto chitosan-epichlorohydrin immobilized on zeolite, the spectra of the sorbent before and after MB sorption were also weakly changed: the most significant differences were also reported close to $1450 \mathrm{~cm}^{-1}$ and around $1659 \mathrm{~cm}^{-1}[50]$.

\subsection{Investigation of sorption properties}

\subsubsection{Effect of $p H$}

The $\mathrm{pH}$ is a critical parameter in the design and optimization of sorption processes because of its dual effect on both the charge of the sorbent (protonation/deprotonation of reactive groups) and the speciation of the solute ( $\mathrm{pH}$ vs. $\mathrm{pH}_{\mathrm{PZC}}$ ). The $\mathrm{pH}_{\mathrm{PZC}}$ of 2-MBI@Chit was found close to 8.3 [42], while the $\mathrm{pK}_{\mathrm{a}}$ of $\mathrm{MB}$ is reported close to 3.8 [51]. Fig. 2 shows the progressive and linear increase of the sorption of MB with the increase of the $\mathrm{pH}$ of the solution; the sorption efficiency (not shown) allows the quasi complete recovery of the dye at $\mathrm{pH} \sim 10$ (sorption efficiency, SE > 92\%), under selected experimental conditions. At $\mathrm{pH}$ below 8.3 , the sorbent is protonated. On the other hand, the dye remains

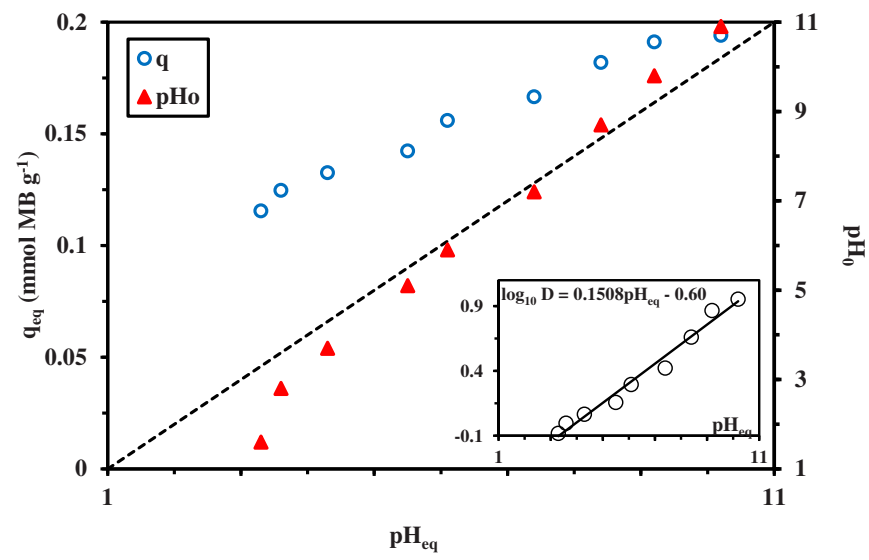

Fig. 2. Effect of $\mathrm{pH}$ on $\mathrm{MB}$ sorption using 2-MBI functionalized chitosan (2MBI@Chit) - sorption capacity, pH variation and distribution ratio ( $\log _{10}$-plot, insert) $\left(\mathrm{C}_{0}\right.$ : $100 \mathrm{mg} \mathrm{MB} \mathrm{L}{ }^{-1}=0.313 \mathrm{mmol} \mathrm{MB} \mathrm{L}^{-1}$; Sorbent dosage, SD: $1.5 \mathrm{~g} \mathrm{~L}^{-1}$; T: $25 \pm 1{ }^{\circ} \mathrm{C}$; Time: $90 \mathrm{~min}$; Agitation speed, v-200 rpm). cationic at $\mathrm{pH}$ below 3.8; meaning that the repulsion effect strongly limits the sorption efficiency in acidic solutions, while the repulsion decreases with increasing the $\mathrm{pH}$ above $\mathrm{pH} 4$. However, $\mathrm{MB}$ sorption at acidic $\mathrm{pH}$ values is non-negligible: for example at $\mathrm{pH}_{0} 1.6$ and $\mathrm{pH}_{\mathrm{eq}} 3.3$, the sorption capacity reaches $0.115 \mathrm{mmol} \mathrm{MB} \mathrm{g}^{-1}$ vs. $0.194 \mathrm{mmol}$ $\mathrm{MB}^{-1}$ at $\mathrm{pH}_{0} 11-\mathrm{pH}_{\mathrm{eq}} 10.2$. This relatively high sorption capacity under unfavorable conditions regarding ionic charges probably means that other mechanisms are involved in the binding of MB on the sorbent. Gayathri and Palanisamy [52] investigated MB sorption on glucose/glucosamine grafted polyacrylamide graphite composite. They reported a series of different potential mechanisms for the binding of $\mathrm{MB}$, including:

(a) H-bonding (between dye ring and - $\mathrm{OH}$ groups of the sorbent),

(b) electrostatic interaction (between protonated sulfur on $\mathrm{MB}$ and $\mathrm{N}$ atoms on the sorbent),

(c) dipole-dipole H-bonding (between $>\mathrm{N}^{\delta-}$ on $\mathrm{MB}$ and $-\mathrm{OH}^{\delta+}$ on the carbohydrate unit), and

(d) $n-\pi$ interaction (between the dye ring and the $\mathrm{O}$ in $\mathrm{OH}$ group or amine groups of the sorbent).

As the $\mathrm{pH}$ increases the protonation of the sorbent decreases, which, in turn, reduces the repulsion effect for the binding of the dye. Sousa et al. [51] investigated the sorption of MB on mineral sorbents (plasma activated palygorskites) and they reported the distribution of protonated $\mathrm{MB}$ species. Different levels of protonation are identified in the range $\mathrm{pH}$ $0-6$. Below pH 1, MB bears 3 cationic charges on $\mathrm{N}$ ( 2 lateral groups and thiazole ring). In the range $\mathrm{pH} 1-2$, trivalent cation co-exists with two divalent cations (2 lateral $\mathrm{N}$ and thiazole/lateral $\mathrm{N}$ group). Between $\mathrm{pH} 2$ and 3 , the predominant species is the divalent species (2 lateral $\mathrm{N}$ groups) with the appearance of increasing amounts of monovalent cationic species (one lateral $\mathrm{N}$ group protonated). Above $\mathrm{pH} 4$, the monovalent cationic species is the unique species present in the solution. The complexity of the system is even increased by the contribution of mesomeric effects (with charge displacement from $\mathrm{N}$ in thiazole to $\mathrm{S}$ ). The increase in sorption capacity is then the double effect of deprotonation of the sorbent and decrease in the number of cationic charges hold by the dye.

Fig. 2 also shows the $\mathrm{pH}$ variation during the sorption of MB. Below the $\mathrm{pH}_{\mathrm{PZC}}$ value, the final $\mathrm{pH}$ is increased compared with the initial $\mathrm{pH}$ value, especially for $\mathrm{pH}_{0}$ below $5.1\left(\mathrm{pH}_{\mathrm{eq}} 5.5\right)$ : by up to $1.4-1.5 \mathrm{pH}$ unit in the most acidic solutions. Above $\mathrm{pH}_{\mathrm{PzC}}$, the final $\mathrm{pH}$ is a little higher than the initial $\mathrm{pH}$ (by less $0.7 \mathrm{pH}$ unit). At $\mathrm{pH}$ above $\mathrm{pH}_{\mathrm{PZC}}$ (i.e., 8.3) the deprotonation of the sorbent makes easier the sorption of the cationic dye: the highest sorption capacities are obtained at $\mathrm{pH}$ close to 10 .

The insert in Fig. 2 shows the $\log _{10}$ plot of the distribution ratio (D = $\mathrm{q}_{\mathrm{eq}} / \mathrm{C}_{\mathrm{eq}}$ ) vs. the equilibrium $\mathrm{pH}$. The data are aligned according to a linear trend with a slope close to +0.15 . In pure ion-exchange mechanisms, this slope is usually correlated to the number of protons exchanged with the solution during its sorption and serves to evaluate the stoichiometric ratio between the reactive groups and the bound solute. Here, the stoichiometric ratio is not coherent with charge stoichiometry. This is another evidence that the binding mechanism is relatively complex and involves different modes of interactions. In the case of MB sorption onto fava bean peel waste, Bayomie et al. [53] also reported that $\mathrm{MB}$ sorption involves both electrostatic and non-electrostatic mechanisms. Scheme 1 shows the tentative mechanisms involved in MB sorption onto 2-MBI@Chit. Further sorption tests have been performed at $\mathrm{pH} 9.3$.

\subsubsection{Effect of sorbent dosage}

Increasing the sorbent dosage improves the recovery of the dye (Fig. 3). However, the beneficial effect of high sorbet dosages is relatively limited: the sorption efficiency only increases from $90.6 \%$ to $95.9 \%$ when the SD increases from 0.5 to $5 \mathrm{~g} \mathrm{~L}^{-1}$. Therefore, the sorption capacity drastically decreases because of the relatively poor use of 


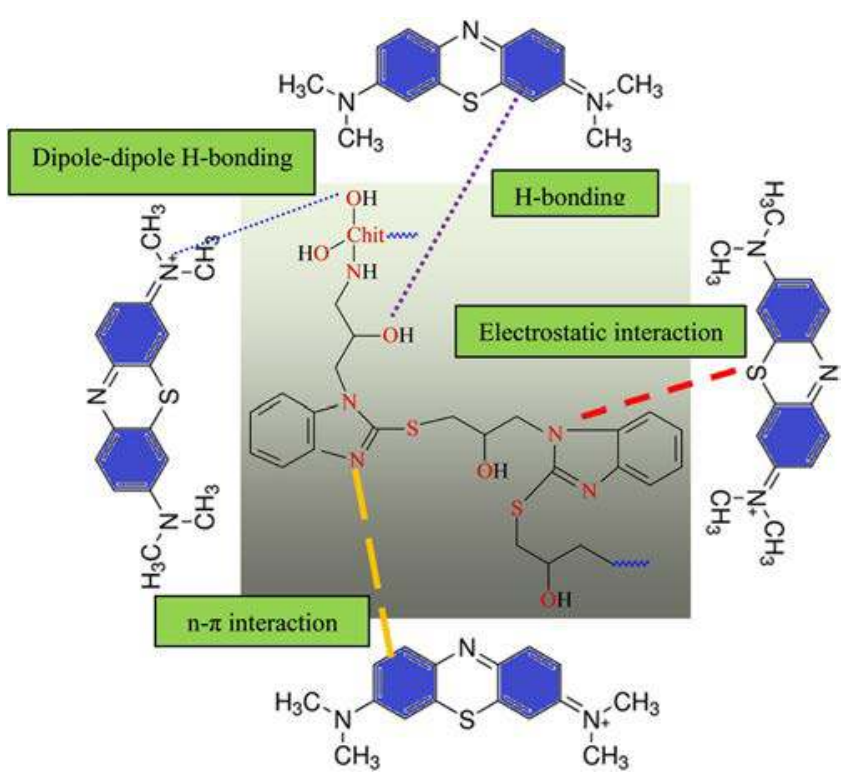

Scheme 1. Suggested mechanisms of MB sorption on 2-MBI@Chit.

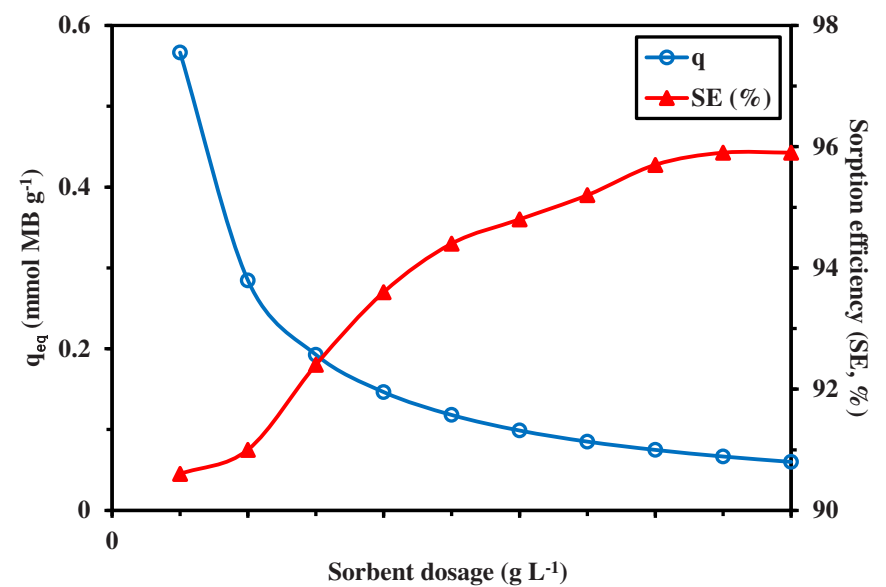

Fig. 3. Effect of sorbent dosage on MB sorption using 2-MBI@Chit - sorption capacity and sorption efficiency $\left(\mathrm{C}_{0}: 100 \mathrm{mg} \mathrm{MB} \mathrm{L}{ }^{-1}=0.313 \mathrm{mmol} \mathrm{MB} \mathrm{L}^{-1} ; \mathrm{pH}\right.$ 9.3; Sorbent dosage, SD: $0.5-5 \mathrm{~g} \mathrm{~L}^{-1}$; $\mathrm{T}: 25 \pm 1{ }^{\circ} \mathrm{C}$; Time: $90 \mathrm{~min}$; Agitation speed, v-200 rpm).

the excess of sorbent compared with dye concentration. Under selected experimental conditions, the sorption capacity drops from 0.567 to $0.06 \mathrm{mmol} \mathrm{MB} \mathrm{g}^{-1}$. For further experiments the sorbent dosage was set to $1.5 \mathrm{~g} \mathrm{~L}^{-1}$; this sounds to be a good compromise between solution exhaustion (removal of the dye) and the saturation of the sorbent.

\subsubsection{Effect of ionic strength (NaCl concentration)}

The sorption performance may be strongly affected by the complexity of the solution. It is thus important to design systems where the sorbent is highly selective for target solute [54]. For instance, in the textile industry dyes may be fixed up using adjuvants such as salts. For this reason, in order to approach the real typology of effluents, the effect of increasing concentrations of $\mathrm{NaCl}$ on the sorption of $\mathrm{MB}$ was investigated. Fig. 4 shows that the presence of salt decreases the sorption efficiency of 2-MBI@Chit for MB binding. Sodium cation may compete with MB for binding onto 2-MBI@Chit. Other mechanisms may be involved in the inhibition of dye sorption including (a) a screening/shield effect (with a simultaneous decrease in the electrostatic interaction between the surface and the sorbate), and (b) the increase in

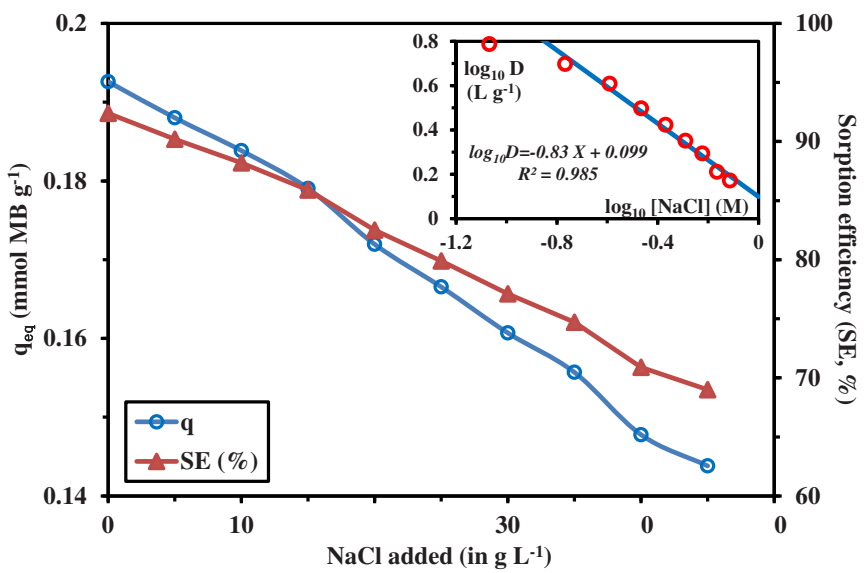

Fig. 4. Effect of the addition of $\mathrm{NaCl}$ on $\mathrm{MB}$ sorption using 2-MBI@Chit sorption capacity and sorption efficiency $\left(\mathrm{C}_{0}: 100 \mathrm{mg} \mathrm{MB} \mathrm{L}{ }^{-1}=0.313 \mathrm{mmol}\right.$ $\mathrm{MB} \mathrm{L}^{-1}$; pH 9.3; Sorbent dosage, SD: $1.5 \mathrm{~g} \mathrm{~L}^{-1}$; $\mathrm{T}: 25 \pm 1{ }^{\circ} \mathrm{C}$; Time: $90 \mathrm{~min}$; Agitation speed, v-200 rpm).

the ionic strength that affects the activity of the dye in the solution [17]. However, even with such as huge excess of $\mathrm{NaCl}$ as $45 \mathrm{~g} \mathrm{~L}^{-1}$ (i.e., $0.77 \mathrm{mmol} \mathrm{L}^{-1}$ ) the sorption efficiency only decreases from $92.4 \%$ to $69.0 \%$. The sorption capacity decreases by $25 \%$ (from 0.192 to $0.144 \mathrm{mmol} \mathrm{MB} \mathrm{g}^{-1}$ ). This means that the sorption system is resilient despite the complexity of the solution. Similar conclusions were commented by Chen et al. [55] for MB sorption onto $\mathrm{Fe}^{3+}$-stabilized magnetic polydopamine composite. In the case of sponge/graphene oxide composite, Nayl et al. [56] reported much higher impact of salinity on MB sorption: sorption efficiency decreases from $\sim 92 \%$ to $\sim 54 \%$ with the addition of $\mathrm{NaCl}$ at the concentration of $10 \mathrm{~g} \mathrm{~L}^{-1}$ (under selected experimental conditions). The insert in Fig. 4 shows the $\log _{10}$ plot of the distribution ratio vs. the concentration of $\mathrm{NaCl}$; in the presence of $\mathrm{NaCl}$ the plots are roughly linear with a slope of -0.83 . The stoichiometric ratio approaches 1; meaning that each dye molecule released is probably exchanged with one $\mathrm{Na}^{+}$ion. The sorbent is very robust in terms of MB sorption in complex solutions; this is a promising property in the perspective of the industrial transfer.

\subsubsection{Uptake kinetics and mass transfer analysis}

The sorption process may be controlled by different mechanisms of heat transfer, mass transfer, and chemical reaction rates. The contributions of resistance to mass transfer have been abundantly documented, including resistances to bulk diffusion, film diffusion, and intraparticle diffusion. A proper agitation mode allows neglecting the resistance to bulk diffusion. On the other side, one of the most important factors affecting the resistance to film diffusion is the agitation speed. The next section compares the kinetic profiles for different agitation speeds. After optimization of this critical experimental parameter, the kinetic profiles are modeled using the Crank equation (resistance to intraparticle diffusion, RIDE) and the conventional chemical reaction rates of first and second-order (these models initially developed for homogeneous chemical reaction have been extended to describe heterogeneous systems): pseudo-first order rate equation (PFORE) and pseudo-second order rate equation (PSORE). The relevant equations are summarized in Table 1.

3.2.4.1. Effect of agitation speed. The sorption capacity of 2-MBI@Chit for $\mathrm{MB}$ is compared (after $90 \mathrm{~min}$ of contact) for different speeds of agitation (in the range 50-300 rpm) (Fig. S3). The contact time set at 90 min mays be insufficient in some cases for reaching the equilibrium. However, this experimental procedure is sufficient for measuring the effect of agitation speed on sorption performance. Increasing the agitation speed linearly increases both the sorption efficiency and 
sorption capacity in the range $50-200 \mathrm{rpm}$. When the agitation speed reaches $200 \mathrm{rpm}$, the sorption performance tends to stabilize; increasing the agitation speed above this limit value is not justified. This agitation speed was selected for sorption tests.

3.2.4.2. Modeling of uptake kinetics. Fig. 5 shows the kinetic profile for the sorption of MB using 2-MBI@Chit under optimized conditions. The equilibrium is reached within $90 \mathrm{~min}$ of contact. Fig. 5 also compares the modeling of experimental data using the PFORE, the PSORE, and the RIDE. Table 1 reports the parameters of these different models. Consistently with Fig. 5, the PFORE fits better experimental profile than the PSORE and the RIDE (as shown by both $\mathrm{R}^{2}$ and AIC values). The higher quality of the PFORE fit is also clearly demonstrated by the calculated values of the sorption capacity at equilibrium (i.e., $0.1936 \mathrm{mmol} \mathrm{MB} \mathrm{g}^{-1}$ ), which is much closer to the experimental value

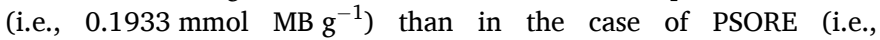
$0.2225 \mathrm{mmol} \mathrm{MB} \mathrm{g}{ }^{-1}$ ) (Table 1 ). The apparent rate coefficient, $\mathrm{k}_{1}$, is close to $0.041 \mathrm{~min}^{-1}$.

The modeling of experimental kinetic profiles is abundantly focused in the literature on PFORE and PSORE models because of the simplicity of the computer facilities required for the determination of apparent constants and the relatively good fit of profiles. However, several contributions recently pointed out the inappropriate use of these simple equations $[57,58]$ for modeling sorption kinetics. Among the possible parameters that introduce bias in the interpretation are the excess of sorbent compared with solute concentration (which drastically changes the residual concentration of the solute that should be kept roughly constant) [58], or sorption capacity too close from the saturation [57], among other possible mistakes in the methodology and design of kinetic studies. More specifically, these studies are concluding that frequently the best fit of experimental data by the PSORE is hiding the control of uptake kinetics by resistance to intraparticle diffusion. Therefore, the direct interpretation of PFORE and PSORE as physically- or chemically-driven mechanisms, respectively, must be considered very cautiously. This may be considered a simple tool for comparing profiles rather than direct interpretation of mechanisms, especially in the case of inappropriate design of experimental conditions.

The RIDE (so-called Crank equation [59]) allows approaching the effective intraparticle diffusion constant $\left(D_{e}\right)$, which is found close to $7.6 \times 10^{-11} \mathrm{~m}^{2} \mathrm{~min}^{-1}$. This is three orders of magnitude lower than the values reported for MB diffusivity in water (i.e., $4.04 \times 10^{-11} \mathrm{~m}^{2} \mathrm{~min}^{-1}$ $[60])$. This means that the resistance to intraparticle diffusion plays a significant role in the overall control of uptake kinetics.

Alternative modeling can bring complementary insight on the sorption/desorption rates process (such as the Elovich equation, $[61,62]$ ) or

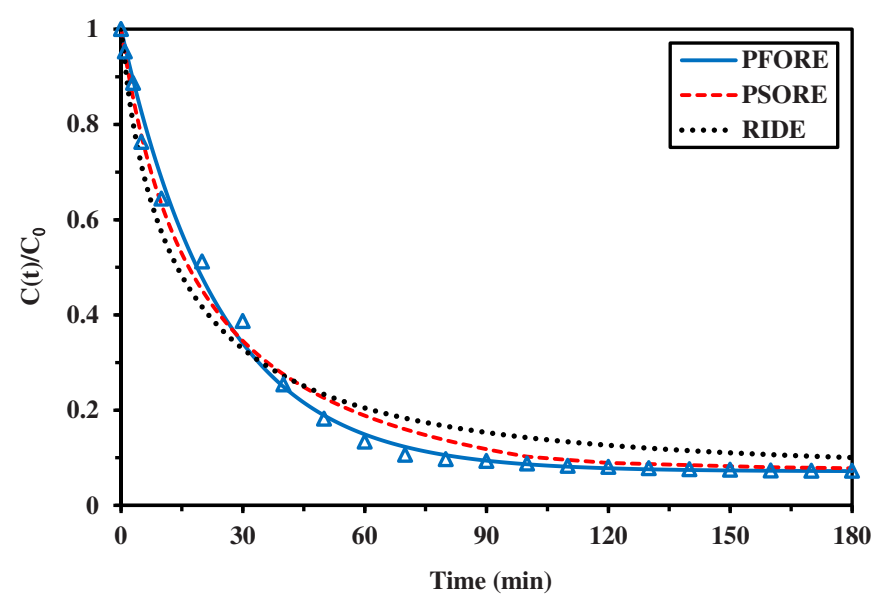

Fig. 5. Uptake kinetics - comparison of fitting model $\left(\mathrm{C}_{0}: 100 \mathrm{mg} \mathrm{MB} \mathrm{L}{ }^{-1}=\right.$ $0.313 \mathrm{mmol} \mathrm{MB} \mathrm{L}{ }^{-1}$; pH: 9.3; Sorbent dosage, SD: $1.5 \mathrm{~g} \mathrm{~L}^{-1}$; $\mathrm{T}: 25 \pm 1{ }^{\circ} \mathrm{C}$; Agitation speed, v-200 rpm). the contribution of the diffusion modes (Weber and Morris equation, [63]) (Fig. S4). Fig. S4a shows that the Elovich equation fits well the initial section of the uptake kinetics (first minutes of contact) but fails to describe the second part of the curve. The plot of the sorption capacity (i. e., $\mathrm{q}(\mathrm{t})$ ) vs. the square root of time allows identifying three sections corresponding to:

(a) the first minutes (usually controlled by the resistance to film diffusion),

(b) the intermediary range, where most of the sorption takes place, which is controlled by resistance to intraparticle diffusion, and

(c) the final section covering the saturation of the sorbent (with a progressive filling of the internal microporous sites).

When the linear plot of sorption capacity against the square root of time does not pass through the origin, it is generally accepted that the resistance to film diffusion is playing a role in the control of mass transfer [64]; this is especially the case within the first minutes of contact. These results confirm the contribution of resistance to intraparticle diffusion in the control of kinetic profiles for the sorption of $\mathrm{MB}$ onto 2-MBI@Chit. The PFORE allows the best mathematical fit of experimental data. It is noteworthy that this fast kinetic performance is improved by sonochemical treatments $[42,65]$.

\subsubsection{Sorption isotherms and thermodynamic parameters}

With increasing the concentration of the dye, it is possible progressively approaching the saturation of the sorbent and establishing the sorption isotherms (Fig. 6). The maximum sorption capacity is close to $1.28 \mathrm{mmol} \mathrm{MB} \mathrm{g}^{-1}$ at room temperature (i.e., $25 \pm 1{ }^{\circ} \mathrm{C}$ ). The sum of $\mathrm{N}$ and $\mathrm{S}$ reactive groups is close to $10.3 \mathrm{mmol} \mathrm{g}^{-1}$. The molar ratio $\mathrm{MB} /$ $(\mathrm{N}+\mathrm{S})$ is close to 0.125 ; this is lower (but of the same order of magnitude) than the calculated stoichiometric ratio (i.e., 0.15) from the slope of the curve $\log _{10} \mathrm{D}$ vs. pH. A steep initial slope, followed by the formation of a saturation plateau, characterizes the shape of the sorption isotherms (carried out at different temperatures, in the range $25-55^{\circ} \mathrm{C}$ ). Both the initial slope and the values of the saturation plateaus (sorption capacity at saturation) slightly increase with the temperature. The sorption of MB onto 2-MBI@Chit is endothermic; this is consistent with the results reported by Al-Ghouti and Al-Absi [66] for the sorption of MB onto olive stones. The modeling of sorption isotherms was processed using conventional equations reported in Table 2.

The shape of the curves is characteristic of systems described by the Langmuir equation; the Freundlich equation is a power-like function (exponential trend), which is not consistent with the saturation plateau.

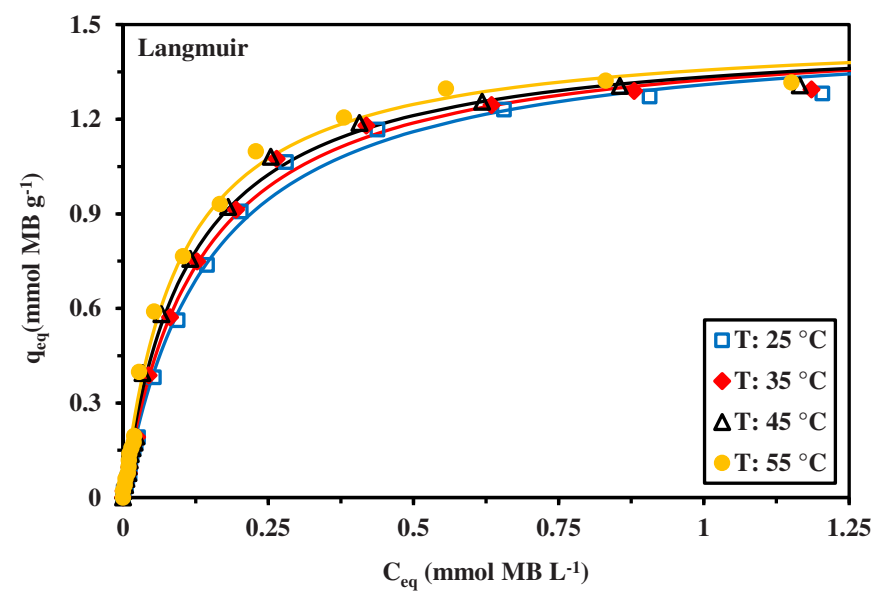

Fig. 6. Effect of temperature on MB sorption isotherms using 2-MBI@Chit Langmuir equation fitting $\left(\mathrm{C}_{0}: 10-1000 \mathrm{mg} \mathrm{MB} \mathrm{L}^{-1}=0.0313-3.13 \mathrm{mmol}\right.$ $\mathrm{MB} \mathrm{L}^{-1}$; pH 9.3; Sorbent dosage, SD: $1.5 \mathrm{~g} \mathrm{~L}^{-1}$; T: $25-55 \pm 1{ }^{\circ} \mathrm{C}$; Time: $90 \mathrm{~min}$; Agitation speed, v-50-300 rpm). 
The Langmuir equation appears to be more appropriate for fitting experimental results. This is consistent with the results summarized in Table 2. The Langmuir equation supposes the sorption to be homogeneous (in terms of the distribution of sorption energies at the surface of the sorbent), and that sorption occurs as a monolayer without interactions between sorbed molecules. The Sips mathematical equation introduces a supplementary adjustable parameter (being a combination of the Langmuir and the Freundlich equations). This third adjustable parameter allows improving the quality of the fit of experimental profiles; the calculation of the AIC parameter (which takes into account the number of adjustable parameters in the models) confirms that this model is significantly better than the Langmuir equation for describing sorption profiles, except at $\mathrm{T}$ : $55^{\circ} \mathrm{C}$. The differences are usually considered significant when the $|\Delta \mathrm{AIC}|>2$. In Fig. 6, the experimental data are fitted by the Langmuir equation (solid lines); the Sips modeling is presented in Fig. S5.

Table 2 shows that the Langmuir modeling overestimates the maximum sorption capacity by $17-12 \%$ (only $9-6 \%$ for the Sips model). The effect of temperature is more significant on the initial slope of the sorption isotherm (correlated with the affinity coefficient of the sorbent for the solute; the initial slope is $\approx \mathrm{q}_{\mathrm{m}, \mathrm{L}} \times \mathrm{b}_{\mathrm{L}}$ ) than on the sorption capacity at saturation (by $3 \%$ between $25{ }^{\circ} \mathrm{C}$ and $55^{\circ} \mathrm{C}$ ). The variations of the affinity coefficients, after conversion into dimensionless parameters $\left(b_{L}{ }^{*}\right.$ and $\left.b_{S}{ }^{*}\right)$ [67] can be used for calculating the thermodynamic parameters using the van't Hoff plots:

$\Delta G^{\circ}=-R T \ln b_{L}^{*}$ or $\Delta G^{\circ}=-R T \ln b_{S}^{*}$

$\Delta G^{\circ}=\Delta H^{\circ}-T \Delta S^{\circ}$

where $\Delta \mathrm{H}^{\circ}\left(\mathrm{kJ} \mathrm{mol}^{-1}\right), \Delta \mathrm{G}^{\circ}\left(\mathrm{kJ} \mathrm{mol}^{-1}\right)$, and $\Delta \mathrm{S}^{\circ}\left(\mathrm{J} \mathrm{mol}^{-1} \mathrm{~K}^{-1}\right)$ are the enthalpy change, the free Gibbs energy change, and the entropy change, respectively (with $\mathrm{T}$ : the temperature in $\mathrm{K}$, and $\mathrm{R}$ : the ideal gas constant). The parameters can be obtained from:

$\ln b_{L}^{*}=-\frac{\Delta H^{\circ}}{R T}+\frac{\Delta S^{\circ}}{R} \operatorname{orln} b_{S}^{*}=-\frac{\Delta H^{\circ}}{R T}+\frac{\Delta S^{\circ}}{R}$

Fig. 7 shows the relevant van't Hoff plots (for both $b_{\mathrm{L}}$ and $b_{S}$ ). The values of the enthalpy change are consistent for the two calculations: $10.84-11.75 \mathrm{~kJ} \mathrm{~mol}^{-1}$, while the entropy change is close to 114.3-112.7 $\mathrm{J} \mathrm{mol}^{-1} \mathrm{~K}^{-1}$. Table 3 summarizes the thermodynamic parameters. The positive values of enthalpy change confirm the endothermic character of the sorption of MB onto 2-MBI@Chit, while the positive values of the entropy change indicate that the randomness of the system increases. With the absolute value of $\left|\mathrm{T} \Delta \mathrm{S}^{\circ}\right|$ being greater than $\left|\Delta G^{\circ}\right|$, the sorption mechanism appears to be controlled by entropy

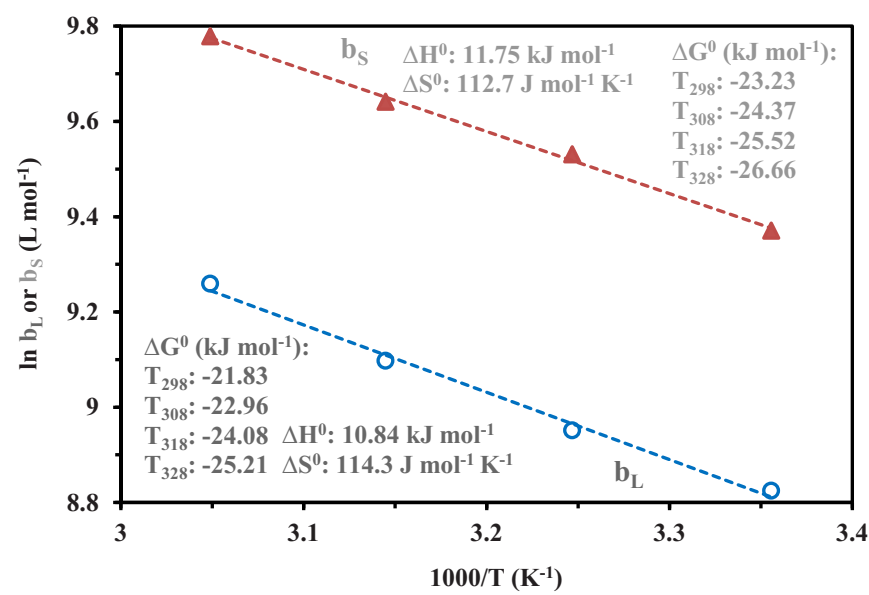

Fig. 7. Analysis of the thermodynamics of MB sorption using 2-MBI@Chit van't Hoff plots (derived from Figs. 5 and S5, with extraction of affinity coefficients from Langmuir and Sips equations, respectively). rather than enthalpy. Shahwan recently discussed in deep the significance of negative values of $\Delta \mathrm{G}^{\circ}$. Contrary to the conventional interpretation on the spontaneity of the sorption process [69], Shahwan, [68] preferred considering that the sorption is only favored when $\Delta \mathrm{G}^{\circ}$ is negative. In addition, he pointed out the importance of considering the contribution of the dehydration effects in the discussion of enthalpy and entropy changes [68]. As a complement to previous comments reported by Lima et al., [67] the appropriate conditions for comparing and interpreting the values of thermodynamic parameters require careful attention and moderation in conclusions.

These orders of magnitude (and the specific relevant characters/ signs of $\Delta \mathrm{H}^{\circ}, \Delta \mathrm{G}^{\circ}$, and $\Delta \mathrm{S}^{\circ}$ values) in the thermodynamics of MB sorption are consistent with the values reported for MB sorption onto $\mathrm{Fe}^{3+}$. stabilized magnetic polydopamine composite [55]. For MB sorption onto cellulosic olive stones, the same trends were observed though the intrinsic values of enthalpy and entropy changes were significantly higher [66]. The enthalpy changes required for MB sorption onto sugarcane bagasse [70], activated carbon/cellulose films [1], and graphene oxide/alkali lignin aerogel [71] are about one order of magnitude lower than for 2-MBI@Chit. The enthalpy changes for gellan-pullulan nanogels were reported around $5 \mathrm{~kJ} \mathrm{~mol}^{-1}$ [2]. On the opposite hand, the sorption of MB onto silica-based sorbents [10] and n-layer aminated graphene oxide [72] shows higher values for the entropy change and high negative values for the enthalpy change.

Several studies have shown the possibility for methylene blue to aggregate in acidic solution [73]; though this effect tends to decrease at neutral or alkaline $\mathrm{pH}$ [74]. This may strongly influence the sorption performance in terms of both kinetics (increase of the volume and size of the solute, which, in turn, may affect the resistance to intraparticle diffusion) and equilibrium (accessibility to internal reactive groups, steric hindrance, stoichiometric ratio between functional groups on the dye and the reactive groups on the sorbent). Li et al. [75] pointed out the strong importance of the adsorption orientations of the dyes molecules on the binding performance (which may be influenced by the temperature). Walker and Weatherley characterized the contributions of dye aggregation and sorbent porosity (activated carbon and bone char) on dye sorption [76]. Luo et al. [77] reported the occurrence of in situ aggregation of adsorbed $\mathrm{MB}$ in the porosity of $\mathrm{WO}_{3}$ nanosheets. These different mechanisms of aggregation (both in liquid and at the surface of the sorbent) may obviously affect the thermodynamics of sorption, especially at the level of entropy effect since the randomness of the system decreases with the aggregation and precipitation of the solute. This mechanism was already documented in the case of amphiphilic molecules [78] and the adsorption of dyes onto anionic surfactant-coated mesoporous aminopropyl silica [79].

The sorption properties of 2-MBI@Chit for MB sorption are compared with the binding performances of alternative sorbents recently reported in the literature (Table S2). The experimental conditions are significantly different, especially in terms of selected $\mathrm{pH}$ values. Apart from this parameter, the criteria of equilibrium time and Langmuir parameters allow roughly comparing these materials. Some materials show outstanding sorption capacities, such as lignocellulosepoly(acrylic acid)/clay composite (i.e., $6.25 \mathrm{mmol} \mathrm{MB} \mathrm{g}^{-1}$, at $\mathrm{pH} 5$ [80]), graphene oxide/lignin aerogel (i.e., $3.62 \mathrm{mmol} \mathrm{MB} \mathrm{g}^{-1}$, at $\mathrm{pH} 7$ [71]) or acrylic acid-grafted multiwall carbon nanotubes (i.e., $1.91 \mathrm{mmol} \mathrm{MB} \mathrm{g}^{-1}$ at pH 7 [81]). With a maximum sorption capacity at saturation of the monolayer close to $1.5 \mathrm{mmol} \mathrm{MB} \mathrm{g}{ }^{-1}, 2-\mathrm{MBI} @$ Chit is part of the most efficient sorbents recently reported: besides, to high sorption capacity, the equilibrium time (90 min, under selected experimental conditions) is one of the shortest among the best sorbents. The combined kinetic and equilibrium properties of 2-MBI@Chit make this material a promising support for the removal of $\mathrm{MB}$ from aqueous solutions.

\subsubsection{Dye desorption and sorbent recycling}

The design of functionalized materials contributes not only to the 
Table 3

Thermodynamic parameters for MB sorption onto 2-MBI@Chit.

\begin{tabular}{|c|c|c|c|c|c|c|c|c|c|c|}
\hline \multirow[b]{2}{*}{$\mathrm{T}(\mathrm{K})$} & \multicolumn{5}{|c|}{ Based on Langmuir fit } & \multicolumn{5}{|c|}{ Based on Sips fit } \\
\hline & $\Delta \mathrm{H}^{0}$ & $\Delta S^{0}$ & $-\Delta G^{0}$ & $\mathrm{~T} \Delta \mathrm{S}^{0}$ & $\mathrm{R}^{2}$ & $\overline{\Delta \mathrm{H}^{0}}$ & $\Delta S^{0}$ & $-\Delta G^{0}$ & $\mathrm{~T} \Delta \mathrm{S}^{0}$ & $\mathrm{R}^{2}$ \\
\hline 298 & 11.75 & 112.7 & 21.83 & 33.58 & 0.993 & 10.84 & 114.3 & 23.23 & 34.07 & 0.997 \\
\hline 308 & & & 22.96 & 34.71 & & & & 24.37 & 35.22 & \\
\hline 318 & & & 24.08 & 35.84 & & & & 25.52 & 36.36 & \\
\hline 328 & & & 25.21 & 36.96 & & & & 26.66 & 37.50 & \\
\hline
\end{tabular}

$\Delta \mathrm{H}^{0}, \Delta \mathrm{G}^{0}, \mathrm{~T} \Delta \mathrm{S}^{0}: \mathrm{kJ} \mathrm{mol}^{-1} ; \Delta \mathrm{S}^{0}: \mathrm{J} \mathrm{mol}^{-1} \mathrm{~K}^{-1}$.

improvement of sorption properties but also to the increase in the cost of the sorbent (and of the process of dye recovery). This means that the recycling of the sorbent is a challenge especially important (compared with low-cost sorbents or biosorbents that could justify a simple step processing). This constraint motivated the investigation of dye desorption and sorbent recycling. Since the study of $\mathrm{pH}$ effect on MB sorption clearly revealed that the efficiency of dye removal increases with the $\mathrm{pH}$. Therefore, the use of acidic solutions appeared as a potential solution for dye release from loaded-sorbent. Preliminary tests (not shown) demonstrated that $0.8 \mathrm{M} \mathrm{HCl}$ solution is highly efficient for dye desorption. Fig. S6 shows the kinetic profile for MB desorption: the fraction of dye released from the sorbent increases almost linearly up to $100 \mathrm{~min}$ (contact time) before tending to stabilize. The maximum desorption (at $140 \mathrm{~min}$ ) reaches up to $94.5 \%$ : a fraction of the dye cannot be released under selected experimental conditions (i.e., SD: $3 \mathrm{~g} \mathrm{~L}^{-1}$, while for uptake kinetics the SD was $1.5 \mathrm{~g} \mathrm{~L}^{-1}$ ). Under these conditions, the sorption is completely reversible but allows concentrating the dye in a smaller volume than for the loading step. Fig. S6 also shows the superposed fits of experimental profiles with both the PFORE and PSORE. The simulated curves roughly follow the experimental trend, despite some inaccuracies are driven by the "wavy-like" shape of the experimental results. It is noteworthy that the PFORE and PSORE fail to fit the final section of the curves: the models suppose the dye to be completely released (contrary to the experimental stabilization of desorption efficiency close to $94.5 \%$ ). Despite the poor quality of these fits (evidenced by the strong overestimation of the calculated initial dye content), the apparent rate constants may be used to roughly compare uptake and desorption rates. Both the PFORE and PSORE apparent rate coefficients for the desorption step are significantly lower than for the uptake. Taking into account specifically the PFORE (which was significantly better for MB sorption than the PSORE), the apparent rate coefficient is decreased from $0.041 \mathrm{~min}^{-1}$ to $0.0052 \mathrm{~min}^{-1}$. This is notable since, in many cases involving the sorption/desorption of metal ions, desorption is generally faster than sorption; a reciprocal trend is observed herein with MB.

Table 4 evaluates the recycling of the sorbent for five successive sorption/desorption cycles (using $0.8 \mathrm{M} \mathrm{HCl}$ solutions as the eluent). The sorption capacity slightly decreases with re-use; however, even after five cycles the loss is less than $5 \%$. The performance stability is even higher in terms of desorption efficiency: the decrease at the fifth cycle is less than 2\%; actually, the desorption efficiency stabilizes at 92.4-92.5\% after the third cycle (against $94.1 \%$ at the first step).

This remarkable stability makes the sorbent very promising for MB recovery (as an example of cationic dyes); although it would be

Table 4

Sorption/desorption cycles.

\begin{tabular}{|c|c|c|c|}
\hline \multirow{2}{*}{$\frac{\text { Step }}{\text { Cycle }}$} & \multicolumn{2}{|l|}{ Sorption } & \multirow{2}{*}{$\frac{\text { Desorption }}{\text { Efficiency (\%) }}$} \\
\hline & $\mathrm{q}_{\mathrm{eq}}\left(\mathrm{mmol} \mathrm{MB} \mathrm{\textrm {g } ^ { - 1 } )}\right.$ & Loss (\%) & \\
\hline$\# 1$ & 0.1928 & - & 94.1 \\
\hline$\# 2$ & 0.1917 & 0.57 & 93.5 \\
\hline$\# 3$ & 0.1903 & 1.30 & 92.4 \\
\hline$\# 4$ & 0.1880 & 2.49 & 92.5 \\
\hline \#5 & 0.1836 & 4.76 & 92.5 \\
\hline
\end{tabular}

necessary to evaluate this performance with complex effluents (which composition could involve the progressive poisoning of the sorbent with competitor solutes, including molecules poorly desorbable). Similar remarkable stability was also reported for sorbents such as n-layer aminated graphene oxide [72] (for 10 cycles) or Saudi red clay [82].

\subsubsection{Dynamic sorption of $M B$ - fixed-bed reactor}

The breakthrough curves may be controlled by many parameters such as the size of sorbent particles and the flow rate (for their respective effects on resistance to intraparticle diffusion and film diffusion), the column height, the concentration of the dye, the temperature, etc. Fig. 8a shows the effect of increasing the flow rate from $240 \mathrm{~mL} \mathrm{~h}^{-1}$ (superficial flow velocity, SFV: $0.306 \mathrm{~m} \mathrm{~h}^{-1}$ ) to $300 \mathrm{~mL} \mathrm{~h}^{-1}$ (SFV: $0.382 \mathrm{~m} \mathrm{~h}^{-1}$ ) (for a column height of $4.89 \mathrm{~cm}$ ). The curves show the characteristic sigmoidal shape. Increasing the flow rate decreases the breakthrough time (corresponding to outlet concentration: $1 \%$ of $\mathrm{C}_{0}$ ): from $373 \mathrm{~min}$ (i.e., $389 \mathrm{BVs}$ ) to $204 \mathrm{~min}$ (i.e., $319 \mathrm{BVs}$ ). On the other side, the exhaustion point (corresponding to $\mathrm{C}_{\text {out }}=0.95 \mathrm{C}_{0}$ ) increases from 1296 BVs (i.e., $1244 \mathrm{~min}$ ) to $1925 \mathrm{BVs}$ (i.e., $1232 \mathrm{~min}$ ) (Table 5). Therefore, the sorption capacity at saturation slightly increases with
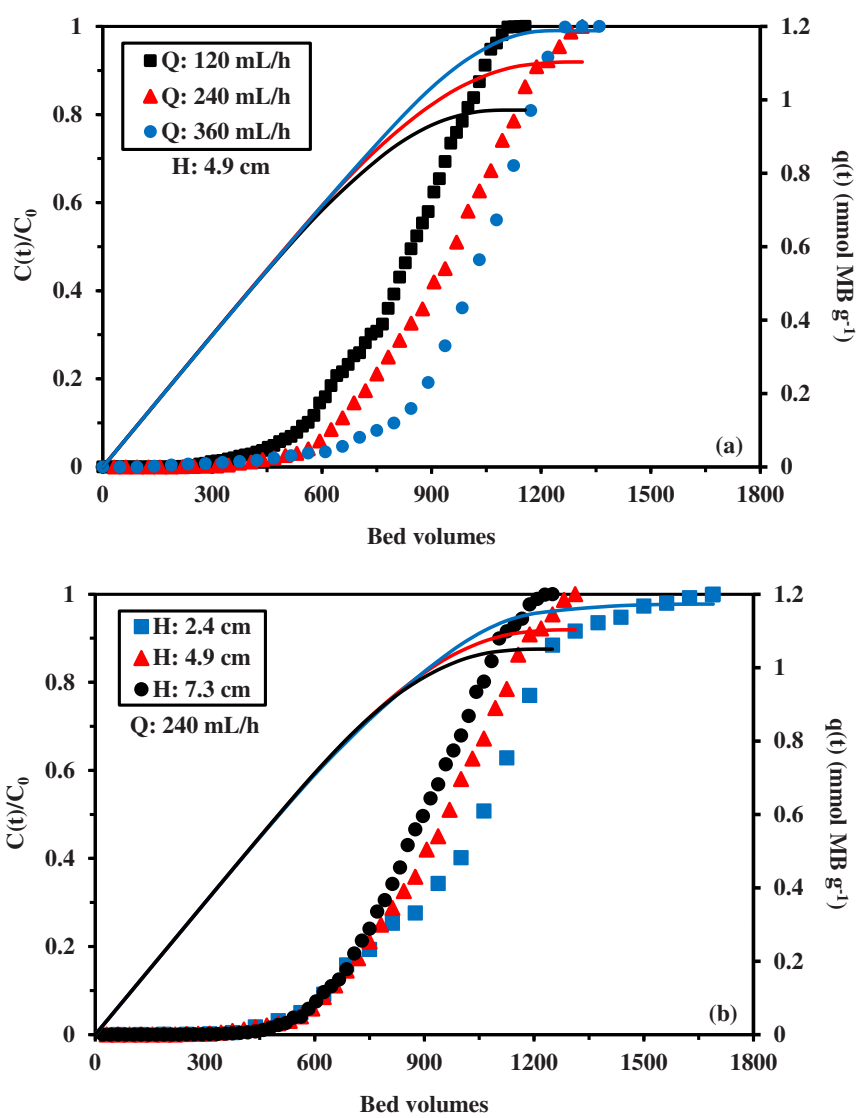

Fig. 8. Breakthrough curves for MB sorption onto 2-MBI@Chit - effect of flow rate (a) and column height (b) (solid lines: sorption capacity $\mathrm{q}(\mathrm{V}) ; \mathrm{C}_{0}$ : $0.625 \mathrm{mmol} \mathrm{MB} \mathrm{L}^{-1} ; \mathrm{pH}_{0}$ : 9.3). 
Table 5

Modeling of breakthrough curves - parameters.

\begin{tabular}{|c|c|c|c|c|c|c|c|c|c|}
\hline $\mathrm{H}$ & $\mathrm{Q}$ & $\mathrm{k}_{\mathrm{YN}} \times 10^{3}$ & $\tau$ & $\mathrm{q}_{\max }$ & $t_{b}$ & $t_{s}$ & $\mathrm{k}_{\mathrm{B}-\mathrm{A}}$ & $\mathrm{N}_{0}$ & $\mathrm{H}_{0}$ \\
\hline 4.89 & 2 & 4.00 & 1627 & 0.972 & 562 & 2054 & & & \\
\hline 4.89 & 6 & 15.4 & 666 & 1.188 & 204 & 1232 & & & \\
\hline 2.45 & 4 & 14.6 & 483 & 1.173 & 194 & 688 & 0.1391 & 298.9 & 0.56 \\
\hline 4.89 & 4 & 7.35 & 915 & 1.103 & 373 & 1245 & & & \\
\hline 7.34 & 4 & 5.20 & 1292 & 1.051 & 653 & 1680 & & & \\
\hline
\end{tabular}

$\mathrm{H}$ and $\mathrm{H}_{0}: \mathrm{cm} ; \mathrm{Q}: \mathrm{mL} \mathrm{min}^{-1} ; \mathrm{k}_{\mathrm{YN}}: \min ^{-1} ; \tau, \mathrm{t}_{\mathrm{b}}$ and $\mathrm{t}_{\mathrm{s}}: \min ; \mathrm{q}_{\mathrm{max}}: \mathrm{mmol} \mathrm{MB} \mathrm{g}{ }^{-1} ; \mathrm{k}_{\mathrm{B}-\mathrm{A}}: \mathrm{L} \mathrm{mmol}^{-1} \mathrm{~min}^{-1} ; \mathrm{N}_{0}: \mathrm{mmol} \mathrm{L}^{-1}$.

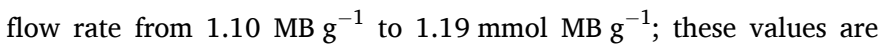
consistent with the sorption isotherms: sorption capacity for $\mathrm{C}_{\mathrm{eq}}$ : $0.625 \mathrm{mmol} \mathrm{L}^{-1}$ is close to $1.28 \mathrm{mmol} \mathrm{MB} \mathrm{g}^{-1}$ (calculated by the Langmuir equation), which corresponds to the maximum sorption capacity ( $\left.\mathrm{q}_{\text {eq,exp }}\right)$.

The increase in flow rate is supposed to reduce the contact time inside the column (for fixed column height); however, this drawback is apparently counterbalanced by a forced flux that allows enhancing the contact of the solution with all the sorbent particles (avoiding preferential channeling). However, these differences are poorly marked.

The amount of sorbent was varied to test various column heights $\left(2.45 \mathrm{~cm}, 4.89 \mathrm{~cm}\right.$, and $7.34 \mathrm{~cm}$ ) (Fig. 8b) at a flow rate of $240 \mathrm{~mL} \mathrm{~h}^{-1}$ (SFV: $0.306 \mathrm{~m} \mathrm{~h}^{-1}$ ). The breakthrough hardly varies with the column height: 389 BVs, 404 BVs, and 453 BVs, respectively. Above 700 BVs, the slope of the curve progressively decreases with increasing the column depth: the residence time increases delaying the exhaustion of the column (i.e., $1170 \mathrm{~min}, 1250 \mathrm{~min}$, and $1438 \mathrm{~min}$ ). The exhaustion time increases with the bed height because the lifetime of the sorption zone increases with the length of the sorption zone [46]. Therefore, the sorption capacity increases with the depth of the column from $1.05 \mathrm{mmol} \mathrm{MB} \mathrm{g}^{-1}$ up to $1.17 \mathrm{mmol} \mathrm{g}^{-1}$.

The Bohart-Adams model was applied considering the evolution of the breakthrough time against the column height (Fig. S7). The capacity of the column is evaluated to $\mathrm{N}_{0}: 299 \mathrm{mmol} \mathrm{MB} \mathrm{L}^{-1}$; this is higher than the values reported for MB sorption on cedar sawdust [83]. Based on an apparent volumetric density of $521 \mathrm{~g} \mathrm{~L}^{-1}$ (i.e.; $1 \mathrm{~g}$ occupying $1.92 \mathrm{~mL}$ ), the sorption capacity stands to $0.574 \mathrm{mmol} \mathrm{MB} \mathrm{g}^{-1}$. This value is significantly higher than the value deduced from the Langmuir equation for an equilibrium concentration $\mathrm{C}_{\mathrm{eq}}=0.00625 \mathrm{mmol} \mathrm{MB}^{-1}$ (i.e., $0.061 \mathrm{mmol} \mathrm{MB} \mathrm{g}^{-1}$ ). This is only a fraction of the sorption capacity available under batch experimentation; similar conclusions were reached in the case of the sorption of reactive yellow with activated carbon [46].

The Bohart-Adams rate coefficient is close to $0.139 \mathrm{~L} \mathrm{mmol}^{-1}$ $\mathrm{min}^{-1}$. These values are of the same order of magnitude as the values reported for the sorption of $\mathrm{MB}$ on cedar sawdust in fixed-bed columns (i.e., $0.142-0.240 \mathrm{~L} \mathrm{mmol} \mathrm{min}^{-1}$ ) [83] or synthetic polymers (i.e., $0.20-0.64 \mathrm{~L} \mathrm{mmol} \mathrm{min}^{-1}$ ) [84]. The equalization of Eq. (6b) to 0 allows determining the $\mathrm{H}_{0}$ value (critical bed height); the value is close to $0.56 \mathrm{~cm}$. This means that the transfer zone is relatively limited and is not controlling the mass transfer of the dye in the fixed-bed. Fig. S8 shows the determination of the parameters of the Yoon-Nelson model, while Fig. S9 compares the experimental profiles with their relevant modeling. The Yoon-Nelson equation remarkably fits the breakthrough profiles, with the notable exception of the exhaustion zone, which is overestimated (requiring longer times or higher volumes, compared with practical application) (Table S3). From Eq. (6b), considering the time $\mathrm{t}_{0.5}$ corresponding to half-reduction of initial concentration $\left(\mathrm{C}_{\text {out }}=\right.$ $0.5 \mathrm{C}_{0}$ ), the right term in the equation cancels out; the plot of $\mathrm{t}_{0.5} \mathrm{vs}$. $\zeta=\mathrm{H} /\left(\mathrm{C}_{0} \times \mathrm{u}\right)$ gives a straight line (Fig. S10). The slope corresponds to $\mathrm{N}_{0}$, the value of the sorption capacity at half-exhaustion: $481.5 \mathrm{mmol} \mathrm{L}^{-1}$; i.e., $0.924 \mathrm{mmol} \mathrm{MB} \mathrm{g}^{-1}$. This value may be compared with the calculated value of the sorption capacity for $\mathrm{C}_{\mathrm{eq}}$ : $0.6125 \mathrm{mmol} \mathrm{MB} \mathrm{L}{ }^{-1}: 1.022 \mathrm{mmol} \mathrm{MB} \mathrm{g}{ }^{-1}$. The loss compared to this theoretical sorption capacity is less than $10 \%$ (i.e., much closer than the loss observed for the breakthrough time, see above).

The BDST application to saturation time $\left(t_{s}\right)$ for varying column height is represented in Fig. S11. The $\mathrm{k}_{\mathrm{BDST}}$ value is close to $0.0222 \mathrm{~L} \mathrm{mmol}^{-1}$. On the other side, the $\mathrm{N}_{0}$ sorption capacity at saturation of the fixed-bed tends to $646 \mathrm{mmol} \mathrm{L}^{-1}$. Taking into account the apparent volumetric density of the bed, the sorption capacity reaches $1.24 \mathrm{mmol} \mathrm{MB} \mathrm{g}^{-1}$; this is consistent with the maximum experimental sorption capacity of 2-MBI@Chit (i.e., $1.28 \mathrm{mmol} \mathrm{MB} \mathrm{g}^{-1}$, Table 2). This also means that all the reactive groups remain accessible in dynamic mode. For each of the tested applications of the BDST model, the straight lines do not pass through the origin; Al-Degs et al. [46] reported that this may be explained by the combination of different rate-limiting steps.

\subsection{Application to MB-spiked industrial effluent}

To evaluate the impact of the complexity of the solution on MB sorption performance, the sorption efficiency and sorption capacity are compared in spiked solutions prepared with either tap water (see Table S4 for composition) or seawater for different dye concentrations (Fig. 9). The sorption capacity linearly increases with initial dye concentration in tap water, while for seawater a slope break is observed at $\mathrm{C}_{0}: 0.0625 \mathrm{mmol} \mathrm{MB} \mathrm{L}^{-1}$ with a loss in sorption capacities of $4.7 \%$ at the lowest dye concentration (i.e., $0.0314 \mathrm{mmol} \mathrm{MB} \mathrm{L}^{-1}$ ). At higher dye concentration, the loss remains almost constant (in the range 15.5-19.8\%). Despite the much complex composition of seawater with high concentrations of $\mathrm{NaCl}$ and other salts, the loss in sorption performance is relatively limited. This is consistent with the observations collected on the effect of $\mathrm{NaCl}$ concentration on $\mathrm{MB}$ sorption from synthetic solutions (Section 3.2.3.). The sorption efficiency (SE) in tap water varies between $93.4 \%$ and $83.9 \%$. In the case of seawater, the SE decreases from $88.7 \%$ (at low concentration) to $70.7-72 \%$ at higher dye concentrations. These trends are consistent with similar observations reported by Ates and Oymak [85] for the sorption of MB from tap water and seawater using biochar produced from persimmon fruit peel (rich in tannins). Under selected experimental conditions, the loss in removal

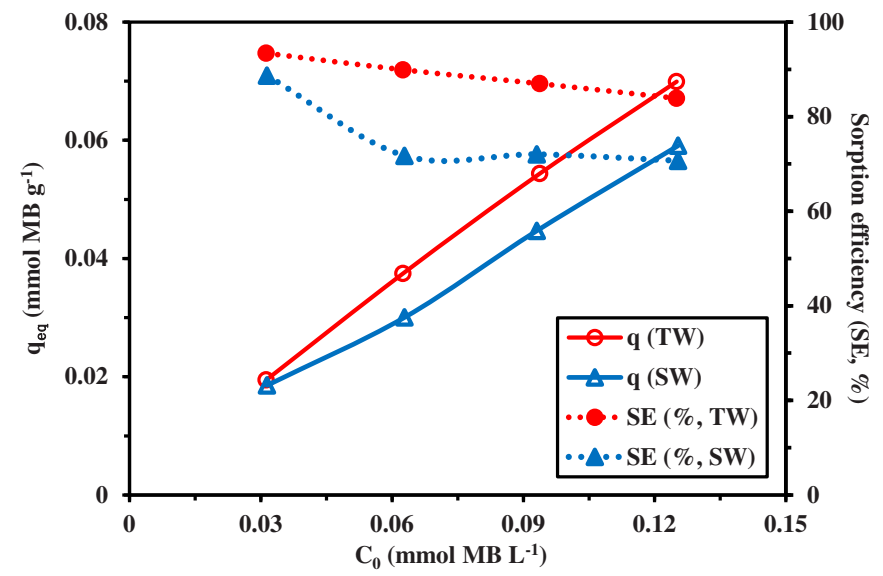

Fig. 9. Treatment of MB-spiked tap water (TW) and seawater (SW) using 2MBI@Chit - effect of MB concentration on sorption capacity and sorption efficiency (pH 9.3; SD: $1.5 \mathrm{~g} \mathrm{~L}^{-1}$; Time: $90 \mathrm{~min}$; v-200 rpm). 
efficiency between seawater and tap water reached 5.9\% (at low dye concentration) and $19.5 \%$ (for higher concentration range). The remarkable stability in sorption performance, including in such complex solutions as seawater, confirms the potential interest of 2-MBI@Chit for wastewater treatment.

\section{Conclusions}

Methylene blue shows a high affinity for 2-MBI@Chit. Different mechanisms (identified by FTIR spectroscopy and the study of $\mathrm{pH}$ effect) may be involved in the removal of the dye, depending on the $\mathrm{pH}$, including: $\mathrm{n}-\boldsymbol{\pi}$ interaction, dipole-dipole $\mathrm{H}$ bonding, $\mathrm{H}$ bonding, and/or electrostatic interaction.

Optimum sorption occurs at $\mathrm{pH}$ 9.3, with a sorbent dosage close to $1.5 \mathrm{~g} \mathrm{~L}^{-1}$ and under an agitation speed of $200 \mathrm{rpm}$ (to reduce the resistance to film diffusion). The resistance to intraparticle diffusion plays a non-negligible role in the control of uptake kinetics; although, the pseudo-first order rate equation fits well the experimental profile. The sorption isotherms are fitted by the Langmuir equation; the sorption is slightly endothermic. The sorption capacities are weakly affected by the presence of $\mathrm{NaCl}$ (up to $45 \mathrm{~g} \mathrm{~L}^{-1}$ ). This property is confirmed by the evaluation of sorption performance in complex MB-spiked solutions (including seawater).

The efficiency of dye desorption reaches $94 \%$ using $0.8 \mathrm{M} \mathrm{HCl}$ and the sorbent maintains remarkable stability in sorption after five successive cycles of sorption/desorption: loss does not exceed $5 \%$ at the fifth cycle.

The breakthrough curves are fitted by the Yoon-Nelson model. The flow rate does not significantly change the slope of the breakthrough curve while increasing the mass of sorbent tends to decrease this slope. The sorption capacities at saturation of the bed are consistent with the sorption capacities collected from the Langmuir equation.

These remarkable properties (summarized by high relative sorption capacities, fast kinetics, high stability at recycling and in the presence of high salinities) make this sorbent highly promising for the recovery of methylene blue (emblematic example of industrial cationic dyes).

\section{CRediT authorship contribution statement}

Khalid Z. Elwakeel: Conceptualization, Methodology, Data curation, Investigation. Ahmed M. Elgarahy: Methodology, Investigation, Writing - original draft. Abdullah S. Al-Bogami: Funding acquisition, Methodology, Investigation. Mohammed F. Hamza: Methodology, Investigation. Eric Guibal: Conceptualization, Investigation, Data curation, Writing - review \& editing.

\section{Declaration of Competing Interest}

The authors declare that they have no known competing financial interests or personal relationships that could have appeared to influence the work reported in this paper.

\section{Acknowledgments}

This work was funded by the University of Jeddah, Saudi Arabia, under Grant No. UJ-20-031-DR. The authors, therefore, acknowledge with thanks the university's technical and financial support. EG acknowledges the support of Institut Français d'Egypte for structuring the collaboration network between IMT-Mines Ales and Egyptian institutions (including Port Said University and Nuclear Materials Authority).

\section{Appendix A. Supplementary information}

Supplementary data associated with this article can be found in the online version at doi:10.1016/j.jece.2021.105609.

\section{References}

[1] N. Somsesta, V. Sricharoenchaikul, D. Aht-Ong, Adsorption removal of methylene blue onto activated carbon/cellulose biocomposite films: equilibrium and kinetic studies, Mater. Chem. Phys. 240 (2020), 122221.

[2] Richa, A.R. Choudhury, Synthesis of a novel gellan-pullulan nanogel and its application in adsorption of cationic dye from aqueous medium, Carbohydr. Polym. 227 (2020), 115291.

[3] T. Yao, L. Qiao, K. Du, High tough and highly porous graphene/carbon nanotubes hybrid beads enhanced by carbonized polyacrylonitrile for efficient dyes adsorption, Microporous Mesoporous Mater. 292 (2020), 109716.

[4] M. Berradi, R. Hsissou, M. Khudhair, M. Assouag, O. Cherkaoui, A. El Bachiri, A. El Harfi, Textile finishing dyes and their impact on aquatic environs, Heliyon 5 (2019), e02711.

[5] O.S. Omer, M.A. Hussein, B.H.M. Hussein, A. Mgaidi, Adsorption thermodynamics of cationic dyes (methylene blue and crystal violet) to a natural clay mineral from aqueous solution between 293.15 and 323.15 K, Arab. J. Chem. 11 (2018) 615-623.

[6] G. Patra, R. Barnwal, S.K. Behera, B.C. Meikap, Removal of dyes from aqueous solution by sorption with fly ash using a hydrocyclone, J. Environ. Chem. Eng. 6 (2018) 5204-5211.

[7] B. Mu, L. Liu, W. Li, Y. Yang, High sorption of reactive dyes onto cotton controlled by chemical potential gradient for reduction of dyeing effluents, J. Environ. Manag. 239 (2019) 271-278.

[8] M. Hasanzadeh, A. Simchi, H.S. Far, Nanoporous composites of activated carbonmetal organic frameworks for organic dye adsorption: synthesis, adsorption mechanism and kinetics studies, J. Ind. Eng. Chem. 81 (2020) 405-414.

[9] G.D. Vyavahare, R.G. Gurav, P.P. Jadhav, R.R. Patil, C.B. Aware, J.P. Jadhav, Response surface methodology optimization for sorption of malachite green dye on sugarcane bagasse biochar and evaluating the residual dye for phyto and cytogenotoxicity, Chemosphere 194 (2018) 306-315.

[10] E.C. Peres, J.C. Slaviero, A.M. Cunha, A.H. Bandegharaei, G.L. Dotto, Microwave synthesis of silica nanoparticles and its application for methylene blue adsorption, J. Environ. Chem. Eng. 6 (2018) 649-659.

[11] F. Afshariani, A. Roosta, Experimental study and mathematical modeling of biosorption of methylene blue from aqueous solution in a packed bed of microalgae Scenedesmus, J. Clean. Prod. 225 (2019) 133-142.

[12] J. Joseph, R.C. Radhakrishnan, J.K. Johnson, S.P. Joy, J. Thomas, Ion-exchange mediated removal of cationic dye-stuffs from water using ammonium phosphomolybdate, Mater. Chem. Phys. 242 (2020), 122488.

[13] C. Shen, Y. Pan, D. Wu, Y. Liu, C. Ma, F. Li, H. Ma, Y. Zhang, A crosslinking-induced precipitation process for the simultaneous removal of poly(vinyl alcohol) and reactive dye: the importance of covalent bond forming and magnesium coagulation, Chem. Eng. J. 374 (2019) 904-913.

[14] A. Szygula, E. Guibal, M. Ruiz, A.M. Sastre, The removal of sulphonated azo-dyes by coagulation with chitosan, Colloids Surf. A Physicochem. Eng. Asp. 330 (2008) 219-226.

[15] Nd.C. Lima Beluci, G.A. Pisano Mateus, C.S. Miyashiro, N.C. Homem, R.G. Gomes, M.R. Fagundes-Klen, R. Bergamasco, A.M. Salcedo Vieira, Hybrid treatment of coagulation/flocculation process followed by ultrafiltration in TIO2-modified membranes to improve the removal of reactive black 5 dye, Sci. Total Environ. 664 (2019) 222-229.

[16] N.C. Dias, J.P. Bassin, G.L. Sant'Anna Jr., M. Dezotti, Ozonation of the dye reactive red 239 and biodegradation of ozonation products in a moving-bed biofilm reactor: revealing reaction products and degradation pathways, Int. Biodeterior. Biodegrad. 144 (2019), 104742.

[17] Y. Liu, S. Huang, X. Zhao, Y. Zhang, Fabrication of three-dimensional porous betacyclodextrin/chitosan functionalized graphene oxide hydrogel for methylene blue removal from aqueous solution, Colloids Surf. A Physicochem. Eng. Asp. 539 (2018) 1-10.

[18] P. Kaur, N. Rajani, P. Kumawat, N. Singh, J.P. Kushwaha, Performance and mechanism of dye extraction from aqueous solution using synthesized deep eutectic solvents, Colloids Surf. A Physicochem. Eng. Asp. 539 (2018) 85-91.

[19] P.T. Lum, K.Y. Foo, N.A. Zakaria, P. Palaniandy, Ash based nanocomposites for photocatalytic degradation of textile dye pollutants: a review, Mater. Chem. Phys. 241 (2020), 122405.

[20] T. O'Mahony, E. Guibal, J.M. Tobin, Reactive dye biosorption by Rhizopus arrhizus biomass, Enzym. Microb. Technol. 31 (2002) 456-463.

[21] A. Pettignano, N. Tanchoux, T. Cacciaguerra, T. Vincent, L. Bernardi, E. Guibal, F. Quignard, Sodium and acidic alginate foams with hierarchical porosity: preparation, characterization and efficiency as a dye adsorbent, Carbohydr. Polym. 178 (2017) 78-85.

[22] M.V. Dinu, M.M. Lazar, E.S. Dragan, Dual ionic cross-linked alginate/clinoptilolite composite microbeads with improved stability and enhanced sorption properties for methylene blue, React. Funct. Polym. 116 (2017) 31-40.

[23] K. Szostak, M. Banach, Sorption and photocatalytic degradation of methylene blue on bentonite-ZnO-CuO nanocomposite, J. Mol. Liq. 286 (2019), 110859.

[24] H. Lyu, B. Gao, F. He, A.R. Zimmerman, C. Ding, J. Tang, J.C. Crittenden, Experimental and modeling investigations of ball-milled biochar for the removal of aqueous methylene blue, Chem. Eng. J. 335 (2018) 110-119.

[25] M.R. Kivanc, V. Yonten, A statistical optimization of methylene blue removal from aqueous solutions by Agaricus campestris using multi-step experimental design with response surface methodology: isotherm, kinetic and thermodynamic studies, Surf. Interfaces 18 (2020). 
[26] R. Sawafta, T. Shahwan, A comparative study of the removal of methylene blue by iron nanoparticles from water and water-ethanol solutions, J. Mol. Liq. 273 (2019) 274-281.

[27] R.H. Moghaddam, A.M.H. Shabani, S. Dadfarnia, Synthesis of new hydrogels based on pectin by electron beam irradiation with and without surface modification for methylene blue removal, J. Environ. Chem. Eng. 7 (2019), 102919.

[28] G.A.F. Roberts, Chitin Chemistry, Macmillan Publishers, Ltd., London (U.K.), 1992.

[29] E. Guibal, Interactions of metal ions with chitosan-based sorbents: a review, Sep. Purif. Technol. 38 (2004) 43-74.

[30] L. Zhang, L. Sellaoui, D. Franco, G.L. Dotto, A. Bajahzar, H. Belmabrouk, A. BonillaPetriciolet, M.L.S. Oliveira, Z. Li, Adsorption of dyes brilliant blue, sunset yellow and tartrazine from aqueous solution on chitosan: analytical interpretation via multilayer statistical physics model, Chem. Eng. J. 382 (2020), 122952.

[31] A. Mokhtar, S. Abdelkrim, A. Djelad, A. Sardi, B. Boukoussa, M. Sassi, A. Bengueddach, Adsorption behavior of cationic and anionic dyes on magadiitechitosan composite beads, Carbohydr. Polym. 229 (2020), 115399.

[32] R. Tabaraki, N. Sadeghinejad, Comparison of magnetic Fe304/chitosan and arginine-modified magnetic Fe304/chitosan nanoparticles in simultaneous multidye removal: experimental design and multicomponent analysis, Int. J. Biol. Macromol. 120 (2018) 2313-2323.

[33] D. Li, X. Tian, Z. Wang, Z. Guan, X. Li, H. Qiao, H. Ke, L. Luo, Q. Wei, Multifunctional adsorbent based on metal-organic framework modified bacterial cellulose/chitosan composite aerogel for high efficient removal of heavy metal ion and organic pollutant, Chem. Eng. J. 383 (2020), 123127.

[34] H. Yakan, M.S. Cavus, E. Guzel, B.S. Arslan, T. Bakir, H. Muglu, Phthalocyanines including 2-mercaptobenzimidazole analogs: synthesis, spectroscopic characteristics, quantum-chemical studies on the relationship between electronic and antioxidant properties, J. Mol. Struct. 1202 (2020), 127259.

[35] W. Chai, Y. Huan, W. Peng, G. Han, Y. Cao, J. Liu, Enhanced separation of pyrite from high-sulfur bauxite using 2-mercaptobenzimidazole as chelate collector: flotation optimization and interaction mechanisms, Miner. Eng. 129 (2018) 93-101.

[36] S. Sharma. Preparation and Characterization of Customized Adsorbents for the Recovery of Palladium from Spent Catalysts and Industrial Wastes (Ph.D. thesis), Department of Chemistry, Birla Institute of Technology and Science, Pilani, India, 2016, p. 183.

[37] S. Sharma, N. Rajesh, 2-Mercaptobenzothiazole impregnated cellulose prepared by ultrasonication for the effective adsorption of precious metal palladium, Chem. Eng. J. 241 (2014) 112-121.

[38] S. Sharma, N. Rajesh, Augmenting the adsorption of palladium from spent catalyst using a thiazole ligand tethered on an amine functionalized polymeric resin, Chem. Eng. J. 283 (2016) 999-1008.

[39] D.L. Guerra, A.C. Batista, R.R. Viana, C. Airoldi, Adsorption of rubidium on raw and MTZ- and MBI-imogolite hybrid surfaces: an evidence of the chelate effect, Desalination 275 (2011) 107-117.

[40] R.L.M. Mesa, J.E.L. Villa, S. Khan, R.R.A. Peixoto, M.A. Morgano, L.M. Gonçalves, M.D.P.T. Sotomayor, G. Picasso, Rational design of an ion-imprinted polymer for aqueous methylmercury sorption, Nanomaterials 10 (2020) 2541.

[41] S. Sharma, M. Barathi, N. Rajesh, Efficacy of a heterocyclic ligand anchored biopolymer adsorbent for the sequestration of palladium, Chem. Eng. J. 259 (2015) 457-466.

[42] K.Z. Elwakeel, A.S. Al-Bogami, E. Guibal, 2-Mercaptobenzimidazole derivative of chitosan for silver sorption - contribution of magnetite incorporation and sonication effects on enhanced metal recovery, Chem. Eng. J. 403 (2021), 126265.

[43] V. Bharti, K. Vikrant, M. Goswami, H. Tiwari, R.K. Sonwani, J. Lee, D.C.W. Tsang, K.H. Kim, M. Saeed, S. Kumar, B.N. Rai, B.S. Giri, R.S. Singh, Biodegradation of methylene blue dye in a batch and continuous mode using biochar as packing media, Environ. Res. 171 (2019) 356-364.

[44] M. Auta, B.H. Hameed, Chitosan-clay composite as highly effective and low-cost adsorbent for batch and fixed-bed adsorption of methylene blue, Chem. Eng. J. 237 (2014) 352-361.

[45] D.C.K. Ko, J.F. Porter, G. McKay, Optimised correlations for the fixed-bed adsorption of metal ions on bone char, Chem. Eng. Sci. 55 (2000) 5819-5829.

[46] Y.S. Al-Degs, M.A.M. Khraisheh, S.J. Allen, M.N. Ahmad, Adsorption characteristics of reactive dyes in columns of activated carbon, J. Hazard. Mater. 165 (2009) 944-949.

[47] E. Ko, H. Kim, Preparation of chitosan aerogel crosslinked in chemical and ionica ways by non-acid condition for wound dressing, Int. J. Biol. Macromol. 164 (2020) 2177-2185.

[48] P. Xu, T. Xu, J. Lu, S. Gao, N.S. Hosmane, B. Huang, Y. Dai, Y. Wang, Visible-lightdriven photocatalytic S- and C- codoped meso/nanoporous TiO2, Energy Environ. Sci. 3 (2010) 1128-1134.

[49] A. Fernandez-Perez, T. Valdes-Solis, G. Marban, Visible light spectroscopic analysis of methylene blue in water; the resonance virtual equilibrium hypothesis, Dyes Pigment. 161 (2019) 448-456.

[50] A.H. Jawad, A.S. Abdulhameed, A. Reghioua, Z.M. Yaseen, Zwitterion composite chitosan-epichlorohydrin/zeolite for adsorption of methylene blue and reactive red 120 dyes, Int. J. Biol. Macromol. 163 (2020) 756-765.

[51] H.R. Sousa, L.S. Silva, P.A.A. Sousa, R.R.M. Sousa, M.G. Fonseca, J.A. Osajima, E. C. Silva-Filho, Evaluation of methylene blue removal by plasma activated palygorskites, J. Mater. Res. Technol. 8 (2019) 5432-5442.

[52] K. Gayathri, N. Palanisamy, Methylene blue adsorption onto an eco-friendly modified polyacrylamide/graphite composites: investigation of kinetics, equilibrium, and thermodynamic studies, Sep. Sci. Technol. 55 (2020) 266-277.
[53] O.S. Bayomie, H. Kandeel, T. Shoeib, H. Yang, N. Youssef, M.M.H. El-Sayed, Novel approach for effective removal of methylene blue dye from water using fava bean peel waste, Sci. Rep. 10 (2020), 7824.

[54] X. Zheng, H. Zheng, Z. Xiong, R. Zhao, Y. Liu, C. Zhao, C. Zheng, Novel anionic polyacrylamide-modify-chitosan magnetic composite nanoparticles with excellent adsorption capacity for cationic dyes and $\mathrm{pH}$-independent adsorption capability for metal ions, Chem. Eng. J. 392 (2020), 123706.

[55] B. Chen, Y. Cao, H. Zhao, F. Long, X. Feng, J. Li, X. Pan, A novel Fe3+-stabilized magnetic polydopamine composite for enhanced selective adsorption and separation of methylene blue from complex wastewater, J. Hazard. Mater. 392 (2020), 122263.

[56] A.A. Nayl, A.I. Abd-Elhamid, A.A. El-Shanshory, H.M.A. Soliman, E.-R. Kenawy, H. F. Aly, Development of sponge/graphene oxide composite as eco-friendly filter to remove methylene blue from aqueous media, Appl. Surf. Sci. 496 (2019), 143676.

[57] J.-P. Simonin, On the comparison of pseudo-first order and pseudo-second order rate laws in the modeling of adsorption kinetics, Chem. Eng. J. 300 (2016) $254-263$.

[58] M.A. Hubbe, S. Azizian, S. Douven, Implications of apparent pseudo-second-order adsorption kinetics onto cellulosic materials: a review, BioResources 14 (2019) $7582-7626$.

[59] J. Crank. The Mathematics of Diffusion, 2nd ed., Oxford University Press, Oxford, U.K., 1975.

[60] A.A. Selifonov, O.G. Shapoval, A.N. Mikerov, V.V. Tuchin, Determination of the diffusion coefficient of methylene blue solutions in dentin of a human tooth using reflectance spectroscopy and their antibacterial activity during laser exposure, Opt. Spectrosc. 126 (2019) 758-768.

[61] J. Zeldowitsch, The catalytic oxidation of carbon monoxide on manganese dioxide, Acta Phys. Chim. URSS (1934) 364-449.

[62] F.-C. Wu, R.-L. Tseng, R.-S. Juang, Characteristics of Elovich equation used for the analysis of adsorption kinetics in dye-chitosan systems, Chem. Eng. J. 150 (2009) 366-373.

[63] W.J. Weber, J.C. Morris, Kinetics of adsorption on carbon from solutions, J. Sanit. Eng. Div. (1963) 31-60.

[64] A.M. Elgarahy, K.Z. Elwakeel, G.A. Elshoubaky, S.H. Mohammad, Untapped sepia shell-based composite for the sorption of cationic and anionic dyes, Water Air Soil Pollut. 230 (2019) 217.

[65] R. Rajumon, J.C. Anand, A.M. Ealias, D.S. Desai, G. George, M.P. Saravanakumar, Adsorption of textile dyes with ultrasonic assistance using green reduced graphene oxide: an in-depth investigation on sonochemical factors, J. Environ. Chem. Eng. 7 (2019), 103479.

[66] M.A. Al-Ghouti, R.S. Al-Absi, Mechanistic understanding of the adsorption and thermodynamic aspects of cationic methylene blue dye onto cellulosic olive stones biomass from wastewater, Sci. Rep. 10 (2020) 15928.

[67] E.C. Lima, A. Hosseini-Bandegharaei, J.C. Moreno-Piraján, I. Anastopoulos, A critical review of the estimation of the thermodynamic parameters on adsorption equilibria. Wrong use of equilibrium constant in the Van't Hoof equation for calculation of thermodynamic parameters of adsorption, J. Mol. Liq. 273 (2019) $425-434$.

[68] T. Shahwan, Critical insights into the limitations and interpretations of the determination of $\Delta \mathrm{Go}, \Delta \mathrm{Ho}$, and $\Delta \mathrm{So}$ of sorption of aqueous pollutants on different sorbents, Colloid Interface Sci. Commun. 41 (2021), 100369.

[69] P. Saha, S. Chowdhury, Insight into adsorption thermodynamics, in: M. Tadashi (Ed.), Thermodynamics, IntechOpen, 2011, p. 18.

[70] T.C. Andrade Siqueira, I.Z. da Silva, A.J. Rubio, R. Bergamasco, F. Gasparotto, E. A. de Souza Paccola, N.U. Yamaguchi, Sugarcane bagasse as an efficient biosorbent for methylene blue removal: kinetics, isotherms and thermodynamics, Int. J. Environ. Res. Public Health 17 (2020), 17020526.

[71] Z. Wu, W. Huang, X. Shan, Z. Li, Preparation of a porous graphene oxide/alkali lignin aerogel composite and its adsorption properties for methylene blue, Int. J. Biol. Macromol. 143 (2020) 325-333.

[72] T.J.M. Fraga, Z.S.B. De Souza, D.M.d.S. Marques Fraga, M.N. Carvalho, E.M.P. De Luna Freire, M.G. Ghislandi, M.A. Da Motta Sobrinho, Comparative approach towards the adsorption of reactive black 5 and methylene blue by n-layer graphene oxide and its amino-functionalized derivative, Adsorpt. J. Int. Adsorpt. Soc. 26 (2020) 283-301.

[73] E.K. Golz, D.A. Vander Griend, Modeling methylene blue aggregation in acidic solution to the limits of factor analysis, Anal. Chem. 85 (2013) 1240-1246.

[74] C.O. Ijagbemi, J.I. Chun, D.H. Han, H.Y. Cho, S.J. O, D.S. Kim, Methylene blue adsorption from aqueous solution by activated carbon: effect of acidic and alkaline solution treatments, J. Environ. Sci. Health A 45 (2010) 958-967.

[75] Z. Li, H. Hanafy, L. Zhang, L. Sellaoui, M. Schadeck Netto, M.L.S. Oliveira, M. K. Seliem, G. Luiz Dotto, A. Bonilla-Petriciolet, Q. Li, Adsorption of congo red and methylene blue dyes on an ashitaba waste and a walnut shell-based activated carbon from aqueous solutions: experiments, characterization and physical interpretations, Chem. Eng. J. 388 (2020), 124263.

[76] G.M. Walker, L.R. Weatherley, Adsorption of dyes from aqueous solution - the effect of adsorbent pore size distribution and dye aggregation, Chem. Eng. J. 83 (2001) 201-206.

[77] J.Y. Luo, Z. Cao, F. Chen, L. Li, Y.R. Lin, B.W. Liang, Q.G. Zeng, M. Zhang, X. He, C. Li, Strong aggregation adsorption of methylene blue from water using amorphous WO3 nanosheets, Appl. Surf. Sci. 287 (2013) 270-275.

[78] K.R. Bickel, A.E. Timm, D. Nattland, R. Schuster, Microcalorimetric determination of the entropy change upon the electrochemically driven surface aggregation of dodecyl sulfate, Langmuir 30 (2014) 9085-9090. 
[79] A.R. Cestari, E.F.S. Vieira, G.S. Vieira, L.E. Almeida, Aggregation and adsorption of reactive dyes in the presence of an anionic surfactant on mesoporous aminopropyl silica, J. Colloid Interface Sci. 309 (2007) 402-411.

[80] Y. Shi, Z. Xue, X. Wang, L. Wang, A. Wang, Removal of methylene blue from aqueous solution by sorption on lignocellulose-g-poly(acrylic acid)/

montmorillonite three-dimensional cross-linked polymeric network hydrogels, Polym. Bull. 70 (2013) 1163-1179.

[81] Y. Huan, G. Wang, C. Li, G. Li, Acrylic acid grafted-multi-walled carbon nanotube and their high-efficiency adsorption of methylene blue, J. Mater. Sci. 55 (2020) 4656-4670.

[82] M.I. Khan, Adsorption of methylene blue onto natural Saudi red clay: isotherms, kinetics and thermodynamic studies, Mater. Res. Express 7 (2020), 055507.

[83] O. Hamdaoui, Dynamic sorption of methylene blue by cedar sawdust and crushed brick in fixed bed columns, J. Hazard. Mater. 138 (2006) 293-303.

[84] A.A. Adeyi, S.N.A.M. Jamil, L.C. Abdullah, T.S.Y. Choong, K.L. Lau, N.H. Alias, Simultaneous adsorption of malachite green and methylene blue dyes in a fixed- bed column using poly(acrylonitrile-co-acrylic acid) modified with thiourea, Molecules (2020) (Basel, Switzerland).

[85] A. Ates, T. Oymak, Characterization of persimmon fruit peel and its biochar for removal of methylene blue from aqueous solutions: thermodynamic, kinetic and isotherm studies, Int. J. Phytoremediat. 22 (2020) 607-616.

[86] Y.S. Ho, G. McKay, Pseudo-second order model for sorption processes, Process Biochem. 34 (1999) 451-465.

[87] A.K. Nayak, A. Pal, Development and validation of an adsorption kinetic model at solid-liquid interface using normalized Gudermannian function, J. Mol. Liq. 276 (2019) 67-77.

[88] C. Tien, Adsorption Calculations and Modeling, Butterworth-Heinemann, Newton, MA, 1994.

[89] I. Langmuir, The adsorption of gases on plane surfaces of glass, mica and platinum, J. Am. Chem. Soc. 40 (1918) 1361-1402.

[90] H.M.F. Freundlich, Uber die adsorption in lasungen, Z. Phys. Chem. 57 (1906) $385-470$ 